Celui-ci n'est pas Keynes: Uma aproximação oblíqua às ideias de John Maynard Keynes

Duarte Gonçalves

Dezembro 2011

WP n. $.2011 / 07$

DOCUMENTO DE TRABALHO

WORKI NG PAPER

DINAMIA'CET

CENTRO DE ESTUDOS SOBRE A MUDA
SOCIOECONOMICA E OTERAITOAID

ISCTE-IUL. 
Celui-ci n'est pas Keynes: Uma aproximação oblíqua às ideias de

John Maynard Keynes

Duarte Gonçalves*

WP no 2011/07

December 2011

Abstract
I - INTRODUÇÃO
II - OBJECTIVOS E MÉTODO
III - INCERTEZA
IV - A INCERTEZA NA ECONOMIA
V - O PAPEL DO ESTADO
VI - O SISTEMA INTERNACIONAL E AS GRANDES GUERRAS
VII - "REVOLUÇÃO METODOLÓGICA"
VIII - REFORMA E SUPERAÇÃO DO CAPITALISMO
IX - ECONOMIC CONSEQUENCES OF KEYNES

* ISCTE-IUL.

Agradecimentos: Não posso perder a ocasião de tornar manifestos os meus agradecimentos à Professora Maria de Fátima Ferreiro por me ter proporcionado a oportunidade de desenvolver este estudo e pelas atentas correcções e sugestões que ajudaram a melhorá-lo, bem como pelos seus conselhos e orientação. Por outro lado, são de referir os importantes contributos de Inês Chaves e de André Cardoso Dias e o auxílio da minha eterna revisora. Por fim, agradeço ao DINÂMIA'CET pelas significativas alterações sugeridas e pela abertura para aceitarem publicar este estudo. A todos, muito obrigado. 


\title{
Celui-ci n'est pas Keynes: Uma aproximação oblíqua às ideias de John Maynard Keynes
}

\section{RESUMO}

Através de fontes secundárias, este estudo pretende mostrar o papel central da incerteza nas teorias de John Maynard Keynes. Recolocando a ênfase sobre este conceito, a partir de uma aproximação à teoria keynesiana das probabilidades, pretendemos destacar as lógicas de Keynes referentes à Economia e o papel que, no âmbito desta, compete ao Estado. Em seguida, são analizados os contributos práticos de Keynes para o forjar do sistema internacional no EntreGuerras e no pós-II Guerra Mundial, bem como a sua reflexão crítica sobre a metodologia económica, devolvendo a Economia, por meio da ideia de organicismo social, ao seio das Ciências Sociais. Depois, identificamos a finalidade do seu sistema com a reforma do capitalismo, tendente à sua própria sublimação. Concluímos com uma breves anotações referentes à forma como foram apreendidas as ideias de Keynes.

PALAVRAS-CHAVE: Keynes; Incerteza; Estado-Providência; Economia; Capitalismo.

\begin{abstract}
Based on secondary sources, this study aims to show the central role of uncertainty in the John Maynard Keynes's theories. Placing the emphasis on this concept, from a Keynesian approach to the theory of probability, we want to highlight Keynes's logic regarding Economics and state's role within it. Next, we analyzed the Keynes's pratical contributions for forging the international system from the Great War onwards and in the post-World War II, as well as its critical reflection on economic methodology, relocating Economics amidst Social Sciences through the idea of social organicism. Then, we identify the purpose of the keynesian system with the reform of capitalism, which tends to its own sublimation. We conclude with brief notes regarding the way that Keynes's ideas were seized.
\end{abstract}

KEYWORDS: Keynes; Uncertainty; Welfare State; Economics; Capitalism. 


\title{
1. INTRODUÇÃO
}

\begin{abstract}
I do not attempt an answer in this place. It would need a volume of a different character from this one to indicate even in outline the practical measures in which they might be gradually clothed.
\end{abstract}

(John Maynard Keynes, 1936) ${ }^{1}$

Assim se pronunciou Keynes relativamente à sua Teoria Geral do Emprego, do Juro e da Moeda e assim introduzimos este estudo. É impossível uma biografia verdadeira de Keynes, mesmo ou sobretudo uma biografia intelectual. O real é descontínuo e a lógica que é urdida pelo género biográfico é sempre ex-post, pelo que é criada pelos próprios biógrafos ${ }^{2}$. Não pretendemos impor uma lógica ao pensamento de Keynes, pelo que abdicamos da caracterização deste ensaio como uma biografia. Também não pretendemos realizar uma metabiografia $^{3}$ das ideias de Keynes, já que a nossa abordagem às diferentes interpretações sobre Keynes foi mais selectiva e interpretativa que compreensiva, perdendo-se muitas das imagens que se criaram sobre este. A primeira, por reconhecimento das limitações metodológicas e condicionantes externas, a segunda por se desviar do nosso móbil.

Qual é então o nosso intuito? Será simplesmente o de executar uma aproximação oblíqua às ideias de Keynes, segundo Pressman, o economista que teve maior impacto sobre o século $\mathrm{XX}^{4}$, senão mesmo um dos maiores de todos os séculos e, simultaneamente, «mais do que um economista» ${ }^{5}$. Uma aproximação que visa relevar a importância central da incerteza na Economia e no real-social, indistrinçável da perspectiva organicista de Keynes sobre a sociedade, re-situando a Economia entre as Ciências Sociais, com uma vincada dimensão moral, humana.

A pertinência actual do tema não podia ser maior, dado não só o estado presente do panorama metodológico da dita “ortodoxia” - termo cunhado pelo próprio Keynes na sua Teoria Geral ${ }^{6}$, com uma relevância acutilante -, como ainda faz este tema derivar a sua

\footnotetext{
${ }^{1}$ KEYNES, 2003.

2 BOURDIEU, 1996.

${ }^{3}$ MAURÍCIO, 2005: 11-15.

4 PRESSMAN, 2006: 157.

${ }^{5}$ SKIDELSKY, 2010: 90.

${ }^{6}$ Sendo que a esta ortodoxia logo no prefácio faz referência - KEYNES, 2003.
} 
actualidade do contexto económico, onde se assomam problemas para os quais parece não existir resposta coerente por entre as teorias económicas dominantes. Jullgamos, por isso, imperativo reconhecer a importância da incerteza keynesiana e todas as ilações a partir desta foram desenvolvidas por Keynes.

\section{OBJECTIVOS E MÉTODO}

O objectivo deste ensaio será então tentar expor ordenamente elementos vários da ou das lógicas de ideias de John Maynard Keynes. Contudo, os nossos interlocutores primeiros serão as fontes secundárias, cujas interpretações das ideias keynesianas (leia-se, de J. M. Keynes) procuraremos trazer e confrontar, transformando-as com a leitura crítica que delas fazemos. É por isso que nos referimos a uma aproximação, dado que não atingiremos a verdadeira lógica das ideias de Keynes, não apenas por lacunas de contacto com as fontes primárias, mas também pela impossibilidade de saber como interpretá-las, algo que possivelmente nem o próprio autor é jamais capaz de o fazer, devido à natureza cambiante das ideias e da posição do indivíduo face ao contexto que o rodeia.

Desta forma, a aproximação não será em "linha recta” à teoria de Keynes, mas mais tributária da aproximação de Ortega y Gasset em $O$ que é a filosofia?, onde pretende «desenvolver o meu pensamento em círculos sucessivos de raio minguante, em rota espiral, portanto» ${ }^{7}$. Apesar de não interpelarmos directamente o autor do cerne deste trabalho, cremos, se não racional, ser pelo menos "razoável”, ter presente a "expectativa” de que os estudos académicos sobre os quais nos baseámos constituírem um repositório fidedigno das teorias deste economista, citando ainda largas passagens das suas obras.

Será uma lógica contestável, mas também a ciência e a procura do comhecimento são, a seu modo, a arte do possível.

\footnotetext{
${ }^{7}$ ORTEGA Y GASSET, 1999: 53.
} 


\section{INCERTEZA}

Se fosse possível reduzir o pensamento de John Maynard Keynes (1883-1946) a uma única palavra, essa palavra seria incerteza. De facto, concordamos com Skidelsky quando este afirma que «o cerne da teoria de Keynes é a existência de uma inescapável incerteza em relação ao futuro» ${ }^{8}$.

A partir deste conceito central, como procuraremos mostrar, é possível fazer desenrolar toda a teoria de Keynes. É a sua porta de entrada $e$, pode-se dizer, a infraestrutura de toda a sua teoria.

\section{Probabilidade}

O desenvolver da questão da incerteza remonta aos tempos de juventude de Keynes, sendo indestrinçável do seu estudo sobre probabilidades, Tratado sobre as Probabilidades ${ }^{9}$, dado que é nele que se gera este conceito revolucionário.

Probabilidade é «uma relação entre proposições», isto é, «uma relação lógica e racional de se conhecer algo a partir da ausência de informação, e de fontes de informação, perfeitas» ${ }^{10}$. Keynes furta-se à definição concreta de probabilidade, que declara impossível, tal como para G. E. Moore (1873-1958), filósofo cuja obra teve uma grande influência em Keynes ${ }^{11}$, era impossível definir "bem”. Como o "bem” e o “amarelo”, probabilidade era uma noção simples e tentar defini-los «em termos de qualquer espécie de factos» era incorrer numa «falácia naturalista» ${ }^{12}$.

Como relação lógica e racional de conhecimento, temos de considerar conhecimento directo de um indivíduo, as informações obtidas e apreendidas imediatamente, a partir das quais se geram as premissas, e conhecimento indirecto, que se reporta à forma como as premissas são

\footnotetext{
${ }^{8}$ SKIDELSKY, 2010: 17. Veja-se também: «A fundamental tenet of Keynes's revolution in economic theory is his argument (KEYNES, 2003: ch. 12) that probabilistic risks, conceptually knowable on the basis of past and present market signals, must be distinguished from uncertainty where existing information is not a reliable guide to future performance» - DAVIDSON, Paul, «Uncertainty in economics», DOW \& HILLARD, 1995: 111.

${ }_{9}^{9}$ Que, embora tenha sido publicado em 1921, sabe-se que começou a ser redigido, pelo menos, em 1905 - SKIDELSKY, 2010: 125

${ }^{10}$ Respectivamente NUNES, 1998: 41 e TERRA \& FERRARI FILHO, 2011: 2.

${ }^{11}$ Moore publica Principia Ethica em 1903, o primeiro ano de Keynes em Cambridge. Influência cuja importância este [Keynes] reconhece na sua memória «My Early Beliefs» (1938): «The large part played by considerations of probability in his [de Moore] theory of right conduct, was indeed an important contributory cause to my spending all the leisure of many years on the study of that subject. I was writing under the joint influence of Moore's Principia Ethica and Russell's Principia Mathematica» NUNES, 1998: 60. Veja-se também LAWSON, Tony, «Economics and expectations», DOW \& HILLARD, 1995: 92.

12 NUNES, 1998: 76-7.
} 
reflectidas pelo indivíduo e transformadas em proposições ou argumentos ${ }^{13}$. A probabilidade traduzia então o grau de crença de um indivíduo relativamente à possibilidade de tornar as suas premissas num argumento ${ }^{14}$. Desta forma, a probabilidade não tinha uma natureza estatística inata, mas lógica: a fonte de conhecimento não era a observação, mas a razão ${ }^{15}$.

No Tratado sobre as Probabilidades, Keynes procede assim à distinção de três tipos de probabilidades. Um primeiro é a probabilidade cardinal ou mensurável (por" exemplo, p(A) = 1/3), viabilizando a comparação através da distância entre os seus valores absolutos, permitindo a avaliação do risco. Um segundo tipo é a probabilidade ordinal, que traduz apenas um «conhecimento vago», qualitativo, dado que é incerto, impossível de medir em termos de valores absolutos, situando-se entre a frequência estatística e a incerteza irredutível por, ainda assim, permitir uma comparação ordinal do tipo $\mathrm{p}(\mathrm{A})>\mathrm{p}(\mathrm{B})$, mas apenas com conhecimento de $\mathrm{p}(\mathrm{A})$ e $\mathrm{p}(\mathrm{B})$ se situarem algures entre 0 e 1 . Por fim, a tríade fica completa com a probabilidade desconhecida, que veicula uma incerteza irredutível, derivada da ausência de informação, lacuna que o tempo preencheria - incerteza epistemológica -, ou de natureza ontológica, sendo «genuinamente irredutível» ${ }^{16}$.

Como se compreende, a teoria probabilística de Keynes não raras vezes passou por “antimatemática”, dado que se pretendeu, efectivamente, romper com o espartilho da lógica formal, alargando-o. À lógica formal, Keynes aduziu a lógica humana, racional e realista e, portanto, reconhecendo a limitação cognitiva. Os juízos de probabilidade eram racionais, porém, já não frequentistas, abarcando o que é provável acontecer, como também o que é razoável acontecer, ultrapassando a concepção aristotélica de probabilidade (o que ocorre usualmente) ${ }^{17}$ para dar conta da complexidade das estruturas do universo, que não são passíveis de ser abrangidas e compreendidas na sua totalidade pelo Homem ${ }^{18}$. Já Alfred Marshal, antigo professor de Keynes, tinha dúvidas com a excessiva matematização do estudo da realidade económica. Para Keynes, a maioria das probabilidades não era passível de ser representada por um cardinal, era, inclusive, não-matemática, embora lógica ${ }^{19}$.

\footnotetext{
13 De referir que a noção de conhecimento derivado de Bertrand Russell já se baseia também em relações probabilísticas e não apenas em relações formais (NUNES, 1998: 36).

14 TERRA \& FERRARI FILHO, 2011: 7.

15 SKIDELSKY, 2010: 126.

${ }^{16}$ SKIDELSKY, 2010: 126-30, NUNES, 1998: 41-6.

${ }^{17}$ NUNES, 1998: 32.

18 NUNES, 1998: 26.

${ }^{19}$ BRADY, 1993: 360: «we can conclude that for Keynes most probabilities were 'non-mumerical».
} 
Sendo lógica, no quadro de uma lógica racional com conhecimento limitado ${ }^{20}$, a probabilidade é apreendida intuitivamente, tratando-se de uma “opinião"21, uma crença, distinguindo-se probabilidade e verdade: algo pode ser razoável ou provável, mas não ocorrer, logo, não ser verdade. Contudo, a probabilidade «respeita ao grau de crença que é admissível ter em certas condições. Uma proposição não é provável porque nós pensamos que o seja», não é subjectiva ${ }^{22}$. Contraria desta forma a estruturação de ideias da Economia clássica de que só existe conhecimento perfeito «baseado na verdade indiscutível» ${ }^{23}$. É, para Keynes, concebível a existência de conhecimento perfeito, mas apenas em circunstâncias muito restritas e para dados fins teóricos ${ }^{24}$.

Se a probabilidade representa a crença de que a premissa se possa tornar num argumento, resultando da comparação entre evidência favorável e evidência desfavorável a um acontecimento, o peso do argumento traduz a evidência disponível, seja quantitativamente seja qualitativa e quantitativamente ${ }^{25}$. Se há mais evidência relevante a suportar um argumento, não significa que haja maior probabilidade, mas que a validade da probabilidade, o peso do argumento, é maior ${ }^{26}$. Não se tem em conta a informação irrelevante, dado que existe informação irrelevante desconhecida, integrando-se somente a evidência relevante ${ }^{27}$. Por outras palavras, «Enquanto a probabilidade mede o grau de certeza ou incerteza da conclusão, o peso mede a incerteza no sentido do grau de confiança» ${ }^{28}$, ou seja, a probalidade da probabilidade ${ }^{29}$.

Na Teoria Geral, Keynes deixa cair a categoria intermédia de probabilidade ordinal para evidenciar o contraste entre incerteza e probabilidade cardinal ou frequentista, segundo Skidelsky ${ }^{30}$. Assim, faz-se corresponder a probabilidade $(T P)$ à expectativa $(T G)$ e o peso $(T P)$ à confiança $(T G)$, sendo a incerteza irredutível sobretudo associada ao longo prazo ${ }^{31}$, o que, em nossa opinião, fere o alcance conceptual e analítico da teoria probabilística de Keynes.

20 Trata-se do conhecimento mediato, dado que a experiência do indivíduo é limitada, cabendo-lhe aperceber-se das evidências, sendo esse o papel atribuído à intuição ou a um juízo a priori, ainda que as probabilididades existem independentemente dos indivíduos - NUNES, 1998: 32-4.

${ }^{21}$ DOW, Sheila, «Uncertainty about uncertainty», DOW \& HILLARD, 1995: 118.

22 NUNES, 1998: 33.

${ }^{23}$ NUNES, 1998: 31.

${ }^{24}$ NUNES, 1998: 41, LAWSON, Tony, «Economics and expectations», DOW \& HILLARD, 1995: 92.

25 NUNES, 1998: 148-9. Esta terminologia, peso do argumento, foi usada inicialmente pelo filósofo C. S. Peirce - vd. BRADY, 1993: 358.

${ }^{26}$ Karl Popper contestou a ideia de peso do argumento, avançando que era paradoxal - BRADY, 1993: 358. Contudo, O’Donnell desmistifica a questão e explica como não tem validade a contestação de Popper a partir da própria lógica interna do Tratado de Probabilidades. Vd. O'DONNELL, 1992.

27 «Keynes's existing rule correctly excludes evidence which has no bearing on the proposition» O'DONNELL, 1992: 47.

${ }^{28}$ NUNES, 1998: 47.

29 O'DONNELL, 1992: 51.

30 SKIDELSKY, 2010: 128.

${ }^{31}$ NUNES, 1998: 127. O conceito de confiança probabilística é contra-intuitivo, logo, difícil de apreender. Por exemplo, Skidelsky confunde expectativa e confiança,ou seja, pode existir uma confiança elevada e 
A questão da probabilidade encontra-se fundada na ideia de incerteza e, sendo dependente da intuição, como matéria de opinião, introduz na Economia a necessidade do estudo da psicologia do indivíduo ${ }^{32}$, nomeadamente quanto à formulação de expectativas. Porém, o indivíduo não é tido como um átomo, senão como um "indivíduo social", na linha do que depois foi o pensamento de Norbert Elias ${ }^{33}$, afectando este pressuposto a perspectiva sobre a realidade económica. Traçámos os temas que procuraremos desenvolver de seguida.

\section{Incerteza}

By uncertain knowledge, let me explain, I do not mean to distinguish what is known for certain from what is only probable. The game of roulette is not subject in this sense to uncertainty [...] Even the weather is moderately uncertain, or the price of copper and the rate of interest twenty years hence [...] About these matters is no scientific basis on which to form incalculable probability whatever. We simply do not know.

(John Maynard Keynes, 1937) ${ }^{34}$

Como atenta, e bem, Jacinto Nunes, «a incerteza é um facto universal da vida» e, acrescentamos nós, a viga-mestra das ideias de Keynes. A Economia clássica ou “ortodoxa”35 toma os indivíduos como detentores do pleno conhecimento «de todas as distribuições de probabilidades relativas a acontecimentos futuros» ${ }^{36}$, actuando os indivíduos, segundo uma lógica de racionalidade formal ou matemática, de acordo com esse conhecimento perfeito. Keynes reconhece que nem toda a actividade económica está pejada de incerteza ${ }^{37}$, mas enfatiza a importância desta, tanto por existir uma incerteza irredutível face ao futuro de longo prazo, como pelo facto de ao estudo da Economia não ser aplicável a ergodicidade estatística, uma vez que o indivíduo em si não é invariante, mas sim imprevisível, tanto mais que as suas acções são interrelacionadas com as de todos os restantes, dado o carácter orgânico daı sociedade, como

uma expectativa pessimista e uma confiança reduzida e uma expectativa positiva - vd. SKIDELSKY, 2010: 125.

32 BRADY, 1993: 359.

33 ELIAS, 1993.

${ }^{34}$ Apud NUNES, 1998: 149.

35 KEYNES, 2003.

${ }^{36}$ SKIDELSKY, 2010: 115.

${ }^{37}$ SKIDELSKY, 2010: 125. 
veremos $^{38}$. A incerteza enfraquece as previsões e correlações da teoria clássica (e neoclássica), pois faz considerar que os números das fórmulas de hoje «é praticamente certo não serem aplicáveis amanhã» ${ }^{39}$.

O’Donnell considera três tipos de incerteza keynesiana: 1) incerteza em relação a uma proposição primária, não se sabendo da sua veracidade ou falsidade, onde a probabilidade mede o grau de certeza ou incerteza; 2) incerteza em respeito à evidência, estando relacionada com o peso do argumento, resultando de se ter, relativamente ao argumento, uma quantidade limitada de informação relevante, sendo que esta não altera o argumento em si, mas o seu peso; 3) incerteza face a uma proposição secundária, sendo as probabilidades desconhecidas pelo seu limitado peso ou escassez de evidência ${ }^{40}$. A incerteza, exibindo diferentes graus, não pode então ser genericamente reduzida ao cálculo da probabilidade, ao risco ${ }^{41}$.

A ideia de incerteza não era completamente alheia à teoria económica, conquanto tivesse sido recalcada do consciente teórico face aos pressupostos irrealistas assumidos de racionalidade e conhecimento perfeito. De facto, já Richard Cantillon (c. 1687 - c. 1734) aborda a incerteza quando se refere à incerteza do impacto do dinheiro - dito "efeito Cantillon" - mas também encarava o futuro em geral como incerto, sendo toda a actividade económica inerentemente arriscada ${ }^{42}$. J. Stuart Mill (1806-1873), por outra parte, dá a nota da incerteza a longo prazo, quando giza cenários de previsão da economia, considerando-os ordinalmente e não cardinalmente, pelo que pode ser tomado como um antecedente de Keynes na determinação da incerteza de longo prazo ${ }^{43}$. Knight, por exemplo, debruça-se também sobre a incerteza do comportamento humano, introduzindo na sua análise outros factores, como as emoções, que não são cientificamente mensuráveis, divergindo dele Keynes ao rejeitar a teoria da competição perfeita e dos mercados eficientes, que Knight apoia ${ }^{44}$.

A incerteza é determinante na economia. Um exemplo claro é o facto de a incerteza influenciar determinantemente o investimento, como veremos. Como refere Hutchinsson, «An analysis of a world with uncertainty in it [...] cannot start from the same assumption of

\footnotetext{
38 TERRA \& FERRARI FILHO, 2011: 5.

39 SKIDELSKY, 2010: 125; NUNES, 1998: 134.

${ }^{40}$ NUNES, 1998: 143-4.

${ }^{41}$ LAWSON, Tony, «Economics and expectations», DOW \& HILLARD, 1995: 91 e BRADY, 1993: 360.

42 PRESSMAN, 2006: 20.

43 «Rather than predicting the ultimate outcome of these conflicting forces, he (Mill 1848, book 4) set forth several possibilities or scenarios for the future. As a result, Mill deserves credit for being the first economist to recognize that long-run trends or outcomes cannot be forecast with certainty» PRESSMAN, 2006: 65-6.

${ }^{44}$ BACKHOUSE, 2002: 202-4.
} 
'rational' conduct as that applicable to a world without uncertainty» ${ }^{45}$. Então, como analisar o comportamento dos indivíduos na sociedade, num contexto de incerteza?

\section{Organicismo}

Thomas Hobbes (1588-1679), no Leviatã, foi o principal teorizador do atomismo ontológico como concepção da sociedade, noção que está na base da Economia clássica e neoclássica. A grande viragem metodológica na percepção social de que o todo não é a soma das partes está já presente nos intelectuais vitorianos, como Ruskin e Coleridge, que se preocupavam com a sociedade como um todo ${ }^{46}$, sendo o princípio das unidades orgânicas mais desenvoltamente concretizado por Moore nos Principia Ethica. Nesta obra, estabelece que todo o Universo é uma unidade orgânica, não sendo passível de se analisar as partes independentemente. Keynes aceita criticamente estas conclusões: o todo não é a soma das partes, mas o princípio das unidades orgânicas deve ser concebido como restrito aos estados da mente individuais ${ }^{47}$.

Nas diversas interpretações sobre as teorias keynesianas, existe uma quesília sobre se a posição deste face à probabilidade era organicista já à data da publicação do Tratado das Probabilidades, se se alterou de atomista para organicista entre este momento e a vinda a lume da Teoria Geral ou se nunca foi abandonada uma posição atomista, controvérsia amplamente explorada por Jacinto Nunes e que nos abstemos de reproduzir ${ }^{48}$. Da nossa parte, partimos do pressuposto, que, a dada altura, Keynes adoptou uma posição organicista, uma vez que ele nos diz que «The atomic hypothesis which has worked so splendidly in physics breaks down in psychics. We are faced at every turn with the problems of organic unity, of discreteness of discontinuity - the whole is not equal to the sum of the parts, comparisons of quantity fail us, small changes produce large effects, the assumptions of a uniform homogenous continuum are not satisfied» ${ }^{49}$. Assim sendo, pensamos ser essencial para compreender as suas ideias uma breve explanação desta visão, dado que logicamente se relaciona com a formulação e alteração das convenções sociais.

O organicismo não toma apenas a sociedade como um todo, mas antes lhe reconhece a interdependência das partes, associando, não somando, os seus efeitos. Lawson chama-lhe «interaccionismo societal», segundo Jacinto Nunes, «uma ideia de Wittgenstein, do próprio Marx e, mais recentemente, de Giddens» ${ }^{50}$. Dada a interacção entre as partes, o todo é constantemente redefinido e, por sua vez, influencia, condiciona a relação entre as partes.

\footnotetext{
${ }^{45}$ NUNES, 1998: 152.

${ }^{46}$ NUNES, 1998: 67.

${ }^{47}$ NUNES, 1998: 81.

${ }^{48}$ NUNES, 1998: 42 e ss.

${ }^{49} \mathrm{~J}$. M. Keynes, apud NUNES, 1998: 116-7.

50 NUNES, 1998: 159.
} 
Rotheim defende que o organicismo social «é o reconhecimento de que a natureza do indivíduo bem como sua percepção de si mesmo são funções de, e mudam com, suas interações com

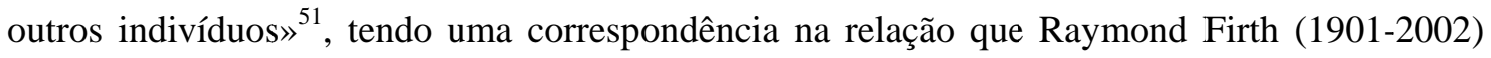
estabelece entre organização e estrutura sociais ${ }^{52}$.

Quais as consequências para a teorização económica decorrentes desta ideia? Em primeiro lugar, a possibilidade de existência de "leis" diferentes para unidades de diferente complexidade, o que naturalmente invalida a sua expressão atómica de leis de relacionamento entre complexos díspares ${ }^{53}$. Por outras palavras, a dois complexos orgânicos distintos podem corresponder "leis" diferentes, ou até opostas, o que torna inviável procurarmos tomar uma "lei" social como derivando do relacionamento entre os “átomos” que compõem o todo. A natureza e complexidade de uma unidade orgânica que integram estes "átomos" tem modos de funcionamento que podem ser distintos de uma outra que os mesmos “átomos" também incorporam: o todo não é mera soma das partes. Segundamente, existe uma relação bívoca entre indivíduo e acontecimento económico, com influência mútua ${ }^{54}$, o que leva a uma reciprocidade causal $^{55}$. Em terceiro, a organicidade do sistema económico traduz-se em relações de interdependência sincrónicas (espaciais) e diacrónicas (temporais), ocorrendo a interpenetração de acções individuais e de práticas sociais ${ }^{56}$, o que cria uma ligação entre as decisões dos vários agentes $^{57}$. Em quarto lugar, a imprevisibilidade da conjugação das partes e acções incrementa o nível de incerteza e limita a capacidade de previsão, quando não gera uma incerteza radical ${ }^{58}$. Por fim, esta visão relaciona-se intimamente com a adopção por Keynes de uma preferência pela "linguagem corrente", o que se deve ao alargamento da lógica formal à humana, preconizado por este, tendo em conta a complexidade da matéria económica. É nesta linha de ideias que se filia a aversão deste pensador ao predomínio do "frequentismo” que denominava de "cálculo benthamita”.

Face a isto, Keynes continua a considerar válida a indução em Economia, dado que o conhecimento parcial proporciona, ainda assim, uma base racional para a intuição, a dedução lógica e a previsão. É por ser incontornável a necessidade de tomar decisões, quer as probabilidades sejam ou não mensuráveis, que se torna legítimo ser a decisão ou um "capricho” individual, uma decisão individual, possivelmente sustentada num arrazoado sobre a evidência

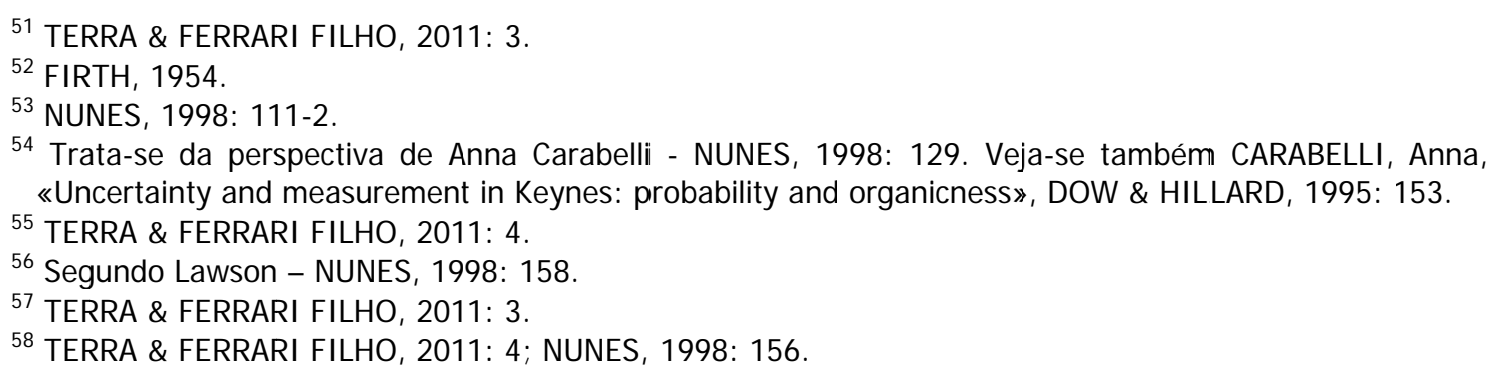

54 Trata-se da perspectiva de Anna Carabelli - NUNES, 1998: 129. Veja-se também CARABELLI, Anna, «Uncertainty and measurement in Keynes: probability and organicness», DOW \& HILLARD, 1995: 153.

55 TERRA \& FERRARI FILHO, 2011: 4.

${ }^{56}$ Segundo Lawson - NUNES, 1998: 158.

57 TERRA \& FERRARI FILHO, 2011: 3.

58 TERRA \& FERRARI FILHO, 2011: 4; NUNES, 1998: 156. 
existente, ou a simples aceitação de uma convenção, como mais tarde Keynes veio a preferir, dada a ênfase da noção de convenção de grupo ${ }^{59}$ sobre o carácter psicológico do processo de tomada de decisão, sendo fundada na intersubjectividade ${ }^{60}$.

\section{Convenções e Expectativas}

Existindo a necessidade de tomar decisões, independentemente do grau de incerteza patente no contexto, os indivíduos utilizam na sua tomada de decisão convenções, isto é, "parâmetros profundos dentro dos quais o comportamento intencional de seres humanos racionais se manifesta» ${ }^{61}$. São as regras e convenções elementos integrantes do sistema orgânico no qual se insere o indivíduo como agente de relações sociais ${ }^{62}$, padrões e condicionantes do comportamento que em muito se assemelham às instituições de pensadoress como Thorstein Veblen (1857-1929) e John R. Commons (1862-1945) ${ }^{63}$. São as convenções que permitem lidar com a incerteza, ou melhor, recalcá-la para o domínio do sub- ou mesmo inconsciente, tranquilizando e dando confiança ao indivíduo ${ }^{64}$, já que se considera razoável, racional até (num âmbito de uma racionalidade que integre a lógica humana), tomar decisões de acordo com estas, como refere Keynes ${ }^{65}$.

A formulação das convenções decorre de forma orgânica, intersubjectiva, sendo o seu expoente máximo a assunção de que o futuro se assemelhará ao passado ${ }^{66}$, algo que o indivíduo sabe não ser verdade, dado que tudo indica o contrário (a História é dinâmica), mas que cimenta a estabilidade social e económica ${ }^{67}$. Não são, portanto, estáticas, mas sim orgânicas. Pelo seu carácter intersubjectivo e essência social, a convenção é criada pelo processo social, sendo passível de sofrer alterações no decurso do tempo. De outra forma dito, as convenções apresentam uma parte formada pelo indivíduo, variando de um para outro indivíduo ${ }^{68}$, e outra pelo conjunto, sendo elas interdependentes ${ }^{69}$. A convenção não é estática, pelo contrário, é dinâmica, mas a sua permanência é de menor volatilidade que a do domínio da crença

${ }^{59}$ Teriam a sua origem na psicanálise - NUNES, 1998: 159-60.

${ }^{60}$ NUNES, 1998: 132, 150. Keynes recusaria, por isso, o subjectivismo, a "aposta" indlividual, no processo de tomada de decisão, não obstante atribuir um lugar definido ao papel da subjectividade, nomeadamente quando não existem probabilidades cardinalmente mensuráveis.

${ }^{61}$ SKIDELSKY, 2010: 124.

62 NUNES, 1998: 156, DAVIS, 1994: 157.

63 Vd. PRESSMAN, 2006: 132-3 e BACKHOUSE, 2002: 195-6, 198-200.

64 SKIDELSKY, 2010: 149, NUNES, 1998: 160.

65 SKIDELSKY, 2010: 129.

${ }^{66}$ NUNES, 1998: 169: «As pessoas tendem a minimizar as futuras mudanças, mesmo quando acreditam que o estado de coisas existente não pode durar indefinidamente». Veja-se também NUNES, 1998: 160.

67 NUNES, 1998: 167-8: «Hábito e convenções têm assim um papel estabilizador no comportamento económico. A essência deste, diz Keynes, é supor que a situação existente continuará por tempo indefinido, excepto quando tenhamos razões concretas para esperar uma alteração. A validade do método assenta portanto na confiança na continuidade da convenção».

68 DAVIS, 1994: 125.

${ }^{69}$ DAVIS, 1994: 128. 
individual, pelo que serve como ancoragem social ${ }^{70}$. Por outro lado, as convenções reflectem o processo de "aprendizagem" humana (social), integrando evidência anterior nas condutas sociais $^{71}$. Sem elas, não seria possível compreender a transformação da actuação individual no contexto social.

Torna-se pertinente referir que a afiliação do conceito de convenção tem relação, mais uma vez, com a obra de Moore, que, questionando-se sobre como maximizar ı "bem universal" num mundo fundamentalmente incerto, defendia dever a solução basear-se em regras sociais ou costumes muito gerais ${ }^{72}$.

É a convenção que intermedeia, como as instituições para os institucionalistas, o comportamento humano e o estado dos factores produtivos ou as condições de escassez ${ }^{73}$. Desta maneira, o social enquadra a acção, sendo por sua vez enformado por esta.

Num período de transformação que seja apercebida de forma mais drástica (sendo-o ou não), a confiança sobre a convenção torna-se reduzida. A convenção, uma regularidade tacitamente assumida pelos agentes, que a utilizam como premissa na qual depositam grande confiança, perde aí a sua pertinência como depositário de confiança e cessa de ser razoável actuar de acordo com ela, algo que retomaremos de seguida.

A partir da teoria das probabilidades, Keynes estabelece a ideia de expectativa que corresponde à noção de probabilidade, considerada por Frank Hahn (1925- ) ${ }^{74}$ o maior contributo da Teoria Geral. A teoria sobre as expectativas keynesiana (de Keynes) distingue-se de uma outra que foi denominada de Hipótese das Expectativas Racionais (HER), pela qual o valor expectável é o valor antecipado pelo modelo de previsão, acrescido do erro aleatório representando a ignorância ou incompetência residual. A HER, desenvolvida por Robert E. Lucas, Jr. (1937- ) e outros teóricos de Chicago ${ }^{75}$, parte de dois pressupostos: o primeiro, que «o indivíduo racional faz um uso eficaz de toda a informação a que tem acesso», o segundo, que o modelo que utiliza para efectuar as suas previsões é o modelo correcto» ${ }^{76}$. A crítica que Skidelsky lhe tece é que o "modelo correcto", segundo a óptica dos teóricos, é o de Chicago, sendo então o comportamento racional o que dispõe expectativas face ao futuro idênticas às dos economistas de Chicago ${ }^{77}$. Outra sensível contestação é a ideia de aplicabilidade, dado que seria

\footnotetext{
${ }^{70}$ KIRSHNER, 2009: 533: «order tends to rest upon crucial (...) foundations».

${ }^{71}$ SKIDELSKY, 2010: 129.

72 LAWSON, Tony, «Economics and expectations», DOW \& HILLARD, 1995: 92.

73 SKIDELSKY, 2010: 124.

74 BLAUG, 1990: 75

${ }^{75}$ NUNES, 1998: 171.

${ }^{76}$ SKIDELSKY, 2010: 64.

77 SKIDELSKY, 2010: 65.
} 
uma teoria aplicável apenas a uma pequena parte da realidade, onde «os processos estocásticos envolvidos são estacionários e ergódicos» ${ }^{78}$.

Keynes, pelo contrário, desenvolveu esta ideia de forma distinta, alargando a concepção de racionalidade subjacente. A sua teoria é de expectativas convencionais, isto é, que é racional ter o princípio do presente como guia, dado que se desconhecem as formas, intensidades e sentidos que tomarão as alterações futuras. A este acresce o princípio de que o estado de opinião existente, traduzido nos preços, é baseado em avaliação correcta das perspectivas futuras. Por fim, a inutilidade do juízo individual, dado que a expectativa média seria talvez melhor informada $^{79}$, o que resulta, afirma Keynes, em tentarmos «agir em conformidade com o comportamento da maioria ou da média» ${ }^{80}$. O processo de formação de expectativas individuais tem como ponto de partida uma expectativa média sobre a expectativa média ${ }^{81}$. Contudo, se a parte se transforma, dada a dependência recíproca entre parte e todo, o todo repercute essa alteração, o que, sendo a relação bívoca, se volta a reflectir sobre a parte, isto porque a expectativa média incorpora em si todas as expectativas individuais.

As expectativas convencionais são assim orgânicas ou intersubjectivas e não atomísticas, e por isso, dinâmicas, qualitativas, dado que a elas se associa um dado grau de confiança, cognitivas, por o conhecimento ser sempre o conhecimento de $\operatorname{algo}^{82}$, objectivas, por se constituírem sobre a evidência relevante disponível ${ }^{83}$. São as expectativas e as convenções factores que limitam a instabilidade da realidade económica, dado que a curto prazo dependemos da confiança nas convenções, seguindo as expectativas convencionais formuladas. Na tomada de decisões a longo prazo, o seu efeito psicológico é de acalmia, não obstante sabermo-las inadequadas, estando também delas dependente a estabilidade das regularidades ${ }^{84}$.

A probabilidade, convém recordar, é distinta de verdade, dado que existir a probabilidade de um argumento ocorrer não se traduz na ocorrência do mesmo. Assim, as expectativas (probabilidades) podem estar erradas ${ }^{85}$. Pelo facto de serem as expectativas um alicerce instável

78 NUNES, 1998: 171. A economia keynesiana é dinâmica e não-ergódica: uma vez que o sistema é irreversível, ou seja, as condições de partida são irrepetíveis e o tempo é irreversível "sendo inaplicável a previsão estatística.

${ }^{79}$ SKIDELSKY, 2010: 135.

${ }^{80}$ Afirma ainda J. M. Keynes: «A psicologia de uma sociedade de indivíduos, em que cada um tenta copiar os outros, conduz àquilo que podemos designar, em sentido estrito, como julgamento convencional» apud SKIDELSKY, 2010: 135.

${ }^{81}$ DAVIS, 1994: 127-8.

82 NUNES, 1998: 38.

${ }^{83}$ ANDRADE, 2000: 86.

${ }^{84}$ NUNES, 1998: 168. Como aponta Winslow, «He also claims that the psychologicial basis of denial is avoidance of anxiety», citando Keynes, «Peace and comfort of mind require that we should hide from ourselves how little we foresee» - WINSLOW, Ted, «Uncertainty and liquidity-preference», DOW \& HILLARD, 1995: 237.

${ }^{85}$ Como nos lembra Hahn, BLAUG, 1990: 75. 
e simultaneamente primordial da tomada de decisão, estão sujeitas a uma alta volatilidade face a informações imediatas, como «uma mudança do noticiário» ${ }^{86}$.A incerteza psicológica que se gera então sobre a confiança nas expectativas e nas convenções tem um efeito disruptivo, que promove um "comportamento de manada”, com a súbita substituição de convenções ${ }^{87}$. É esta a base teórica que fundamenta a expressão animal spirits, adaptada de Descartes a uma ideia freudiana de acto mental inconsciente ${ }^{88}$. Os espíritos animais são, para Keynes, uma marca fulcral dos investidores, levando-os a empreendimentos arriscados caracterizados pela incerteza irredutível do futuro, o que se desconhece e não se pode conhecer ${ }^{89}$. Assim, está o mercado sujeito a ondas de optimismo e pessimismo, sem sentido, face à inexistência de uma «base sólida para um cálculo razoável», mas por isso mesmo legítimas ${ }^{90}$. Não ciclos de negócio (Hayek), nem de inovação (Schumpeter): espíritos animais movidos pelas expectativas, pela confiança nas expectativas, em suma, pela incerteza. Uma consequência disfuncional dos negócios, agravada pela dissociação entre capital e gestão e pela emergência dos voláteis (e volúveis) mercados bolsistas, que sublinham a importância do optimismo ou pessimismo espontâneo dos investidores, decorrentes de uma construção de expectativas sobre expectativas, em detrimento de uma já de si incerta expectativa face à evolução dos factores produtivos ${ }^{91}$.

Keynes demarca-se - e afirma-o - da postura “ortodoxa”. Aponta dois métodos para lidar com o futuro: cálculos e convenções ${ }^{92}$. Declara o primeiro ser uma «false rationalization [that] follows the lines of Benthamite calculus», ignorando o impacto da dúviida, precariedade, esperança e medo sobre o comportamento humano ${ }^{93}$. Pelo contrário, não é demais reforçar, são os instintos espontâneos e os motivos, expectativas e incertezas psicológicas individuais que marcam decisivamente a realidade económica ${ }^{94}$.

\footnotetext{
${ }^{86}$ SKIDELSKY, 2010: 135.

87 TERRA \& FERRARI FILHO, 2011: 8. Veja-se também SKIDELSKY, 2010: 136: «A procura de "prova social" (...) poderá ser um instinto de sobrevivência».

${ }^{88}$ NUNES, 1998: 160.

${ }^{89}$ KIRSHNER, 2009: 532.

90 SKIDELSKY, 2010: 135.

91 DAVIS, 1994: 126. Veja-se também a seguinte passagem: «Indeed, a "calculated mathematical expectation", were it to be possible or appropriate, would at the very least reflect an individual knowledge of the specific facts surrounding a particular investment. Yet since the separation of ownership and management, the in-house acquaintance with firm operations necessary for this knowledge and such a calculation rarely exists for most investors. Ironically, with this separation, the technique of judging the significance of collections of the various facts available to them that will improve on average expectation. As a result of an unstable balance between an average expectation that is invariably wrong yet accepted and each individual's specific judgments which lack firm foundation yet offer at least the promise of doing better than average thinking. It is this combination that makes it necessary to regard a convention as a structure of expectations - a structure, it should still be emphasized, that is always rooted in a specific historical setting»- DAVIS, 1994: 129.

${ }^{92}$ WINSLOW, Ted, «Uncertainty and liquidity-preference», DOW \& HILLARD, 1995: 235.

93 Keynes, apud KIRSHNER, 2009: 532.

${ }^{94}$ DAVIS, 1994: 133.
} 
A teoria económica de Keynes é toda ela construída a partir do princípio da incerteza. Vejamos agora as implicações práticas desta conceptualização.

\section{A INCERTEZA NA ECONOMIA}

Um comentário interessante que escutámos acerca da teoria económica de Keynes, stricto senso, é Keynes "pôr a teoria clássica a fazer o pino”. De facto, partindo da incerteza e não da certeza racionalizada, Maynard procede na contestação, ou mesmo inversão, da teoria "ortodoxa”, sistematizando vários contributos que modela de forma original.

\section{Moeda e Poupança}

Principiemos com a constatação de o dinheiro ser uma convenção social humana para fazer face à incerteza ${ }^{95}$. A teoria clássica classifica a moeda como um mero véu que intermedeia a troca de bens, sendo estéril em $\mathrm{si}^{96}$. Os preços corresponderiam a um rácio entre as quantidades de bens trocados entre si, libertando-se os indivíduos da moeda o mais rapidamente possível ${ }^{97}$. Era a teoria quantitativa da moeda, cujas bases foram lançadas por Thomas Gresham (c. 1519-1579) e John Locke (1632-1704) ${ }^{98}$, que pressupõe que, não tendo o dinheiro qualquer utilidade em si, a duplicação da quantidade de moeda em circulação iria reflectir-se na duplicação do preço dos bens, teoria desenvolvida mais tarde por Milton Friedman (1912-2006) ${ }^{99}$. A crítica keynesiana diz-nos que o pressuposto que se esconde nesta perspectiva é de que a economia era de trocas reais, sendo o dinheiro um elemento neutro, não influenciando as decisões dos agentes ${ }^{100}$.

Pelo contrário, segundo Keynes, o dinheiro comporta-se como um «reservatório de valor», uma parte integrante da economia de mercado, uma economia monetarizada, concretizando uma ligação entre presente e futuro ${ }^{101}$.

Sendo um reservatóro de valor, há motivos lógicos para preferir possuí-la em detrimento de dispender moeda o mais rapidamente possível. A preferência por liquidez, sendo a liquidez máxima a posse de numerário, é justificada por motivos razoáveis e instintivos ${ }^{102}$, sendo o principal, já referido, o de fazer face à incerteza, isto é, acalmar o desassossego perante a falta de confiança. Três são os motivos tradicionalmente apontados para a preferência-liquidez: o motivo-transacção, ou seja, para realizar os pagamentos correntes; o motivo-precaução,

\footnotetext{
95 SKIDELSKY, 2010: 115.

${ }^{96}$ Um contributo cujas raízes remontam já a longínqua doutrina cristã.

97 SKIDELSKY, 2010: 119, HILLARD, John, «Keynes, interdependence and the monetary production economy», DOW \& HILLARD, 1995: 251.

98 PRESSMAN, 2006: 16.

99 PRESSMAN, 2006: 237.

100 WINSLOW, Ted, «Uncertainty and liquidity-preference», DOW \& HILLARD, 1995: 238.

101 SKIDELSKY, 2010: 119, 265.

102 SKIDELSKY, 2010: 138 e WINSLOW, Ted, «Uncertainty and liquidity-preference», DOW \& HILLARD, 1995: 232.
} 
relacionado com a incerteza, para pagamentos inesperados; e o motivo-especulação, dado que a posse de numerário permite que, pelo menos, o activo que se detém não se desvalorize em termos nominais. Nesse caso, quanto menor a confiança, maior a preferência-lliquidez, o que faz com que a taxa de juro seja (também) um prémio de renúncia à liquidez, um «pagamento pelo aumento do sentimento de conforto e confiança que a sua posse [de numerário] conferia ao possuidor» ${ }^{103}$, distinguindo-se do prémio de risco, a recompensa da abdicação de determinado montante de riqueza, no sentido de receber uma maior quantidade (quantidade abdicada e

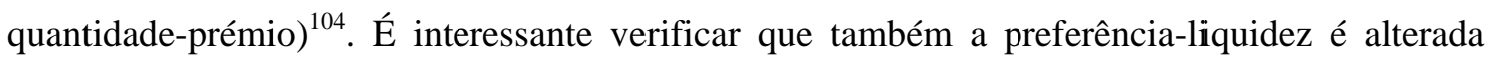
mediante convenções sociais, tendo existido uma translacção da concepção de liquidez privilegiando a posse de propriedade fundiária para a preferência de numerário, como refere Winslow $^{105}$. Esta ideia pode ser ainda complexificada pela imiscuição de factores sociológicos, como o desejo de poder e estatuto (status social), que, infelizmente, não tem cabimento tratar mais desenvolvidamente neste ensaio.

Esta liberdade de não gastar, que caracteriza uma economia monetária é a premissa de Keynes para proceder à refutação da suposta "Lei de Say”"106, que afirma a oferta gerar a sua própria procura, não existindo pelo empresário qualquer expectativa de procura quando produz um serviço, pois esta produção é «motivada pela utilidade que será alcançada ao se trocar os frutos da produção por algum outro bem ou serviço pretendido» ${ }^{107}$. Uma vez que existia a possibilidade de nem todo o rendimento ser gasto, Keynes afirma ser a procura agregada ou total que determina a oferta da produção ${ }^{108}$.

\section{Consumo}

O consumo era um dos destinos do rendimento. Sobre ele Keynes labora uma "lei psicológica", pela qual se afirma que, com um determinado aumento da quantidade de rendimento (A), ocorreria um aumento do consumo (B), mas de nível inferior (A>B). O inverso também era válido, ou seja, a uma diminuição do rendimento correspondia uma diminuição do consumo, mas em proporção inferior (ou seja $|\mathrm{A}|>|\mathrm{B}|$ ). Isto resulta na assunção de que o consumo seria relativamente mais estável que o rendimento, pelo que «confere ao sistema uma certa medida de estabilidade» ${ }^{109}$. O rácio entre os dois aumentos é a propensão ao consumo, que decresceria em relação inversa à quantidade do rendimento, isto é, se um indivíduo aufere um rendimento superior relativamente a outro indivíduo, a propensão ao consumo do primeiro é inferior à do

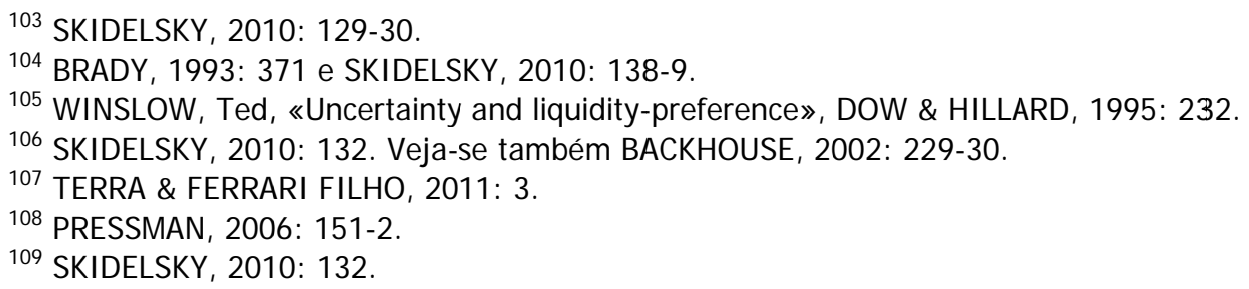


segundo. A propensão marginal ao consumo era decrescente respectivamente a um aumento do rendimento.

Influenciando o consumo encontramos factores subjectivos, como a incerteza face ao futuro, o desejo de obter riqueza e o desejo de disfrutar de independência e: poder, e factores objectivos, as variáveis económicas, sobretudo o rendimento auferido, mas também outras como as taxas de juro, os impostos, a distribuição de rendimento e a desigualdade na distribuição de riqueza e expectativas quanto ao rendimento futuro ${ }^{110}$. Davis, por sua vez, identifica três factores psicológicos fundamentais, respeitando a afectação de rendimento, sendo eles a propensão ao consumo, a preferência-liquidez e a expectativa face ao retorno do capital investido, dependendo estes do estado de confiança e das expectativas face ao futuro, em suma, da incerteza ${ }^{111}$.

Decorrente da primazia da procura sobre a criação de oferta, da preferência-liquidez e da propensão ao consumo, Keynes identifica o "paradoxo de prosperidade”, que se traduz na inevitabilidade da falência do sistema pelo aumento do rendimento. Viejamos, se todos prosperarem, obtiverem maior rendimento, a propensão ao consumo é menor, com um aumento da poupança associado, pelo que resulta numa diminuição da procura agregada, reduzindo, em consequência, a oferta, excepto se o incentivo ao investimento aumente. «Assim, quanto mais “próspera” for uma sociedade, mais dificuldade terá em manter o pleno emprego”»" ${ }^{112}$.

\section{Investimento}

O rendimento obtido por um indivíduo é dividido em três parcelas genéricas, consumo, investimento e poupança, sendo esta última parcela definida como um resíduo entre o rendimento e as restantes duas partes. A procura agregada é então a procura de consumo e a procura de investimento agregadas, sendo esta que determina, como indicámos, o volume de produção e, logo, o de emprego. Sendo que o consumo era razoavelmente estável, a instabilidade do sistema era principalmente atribuída por Keynes ao investimento ${ }^{113}$. Contrariamente aos clássicos, que consideravam a poupança era igual ao investimento, não concebendo fugas do circuito económico ${ }^{114}$, a Economia de Keynes demarca-se: existe uma fuga do fluxo ${ }^{115}$, uma vez que a poupança não consiste num aumento de investimento, mas em

\footnotetext{
110 PRESSMAN, 2006: 152.

111 DAVIS, 1994: 121-3.

112 SKIDELSKY, 2010: 133 e BLAUG, 1990: 11.

113 TERRA \& FERRARI FILHO, 2011: 17 e SKIDELSKY, 2010: 132.

114 Para os "ortodoxos", eram as taxas de juro que equilibravam o nível de gastos com o nível de poupança, algo que Keynes rejeita pela sua própria perspectiva sobre a mesma, como prémio de renúncia à liquidez e prémio de risco. Para este, o equilíbrio entre gasto e poupança devia-se ao volume do rendimento - $v d$. BLAUG, 1990: 12.

115 BLAUG, 1990: 12.
} 
grande medida na procura de numerário, ou seja, na procura de liquidez máxima ${ }^{116}$, estando directamente relacionada com a evolução da incerteza face à expectativia de retorno dos investimentos.

A teoria de investimento de Keynes aproxima-se da de Fisher, estando o nível de investimento dependente do retorno esperado (eficiência marginal do capital) e da taxa de juro, com uma relação inversa entre os dois ${ }^{117}$. O investimento de capital a prazo está sujeito a uma incerteza irredutível, pois a distância temporal que separa o momento da tomada de decisão e o momento esperado de obtenção de retorno de investimento trará consigo alterações sobre as quais não temos quaisquer previsões, sendo que todas as alterações, em maior ou menor grau, afectarão o negócio pela natureza orgânica da realidade social. A natureza, quantidade e intensidade das variáveis é desconhecida, é incerta. Pretender o contrário corresponde a pretender saber o futuro, algo que acreditamos não ser possível. Daí a importância do acto de investimento, pois, estando os retornos adiados para uma data distante ou inclusive indefinida, pode-se dizer corresponderem a «actos de fé» ${ }^{118}$, correspondendo a expectativas acertadas ou não. Podemos então recentrar a ideia de expectativa face à eficiência marginal, não sobre um cálculo racional das condições futuras, mas sim sobre as expectativas, a confiança e as convenções sobre as quais assentam, que podem alterar-se subita e radicalmente, tendo sobre o investimento uma importância central os “espíritos animais”119.

A emergência do mercado accionista reduz a incerteza inerente a todo o investimento, pretendendo-o líquido para o indivíduo, mas sendo fixo para o conjunto. Porém, tornando o investimento mais líquido, torna-o mais susceptível à preferência-liquidez e à flutuação das expectativas, pelo que aumenta a volatibilidade da realidade económica, com o paradoxal resultado de, enfim, aumentar a instabilidade e a incerteza. Por outro lado, tem uma natureza contraditória por pretender dotar de maior liquidez o investimento individual, embora seja impossível a liquidez simultânea de todos os accionistas ${ }^{120}$. A incerteza coloca uma forte relevância na especulação profissional bolsista a curto prazo, que afecta, por sua vez, o investimento de capital, causando grande instabilidade ${ }^{121}$.

Como resultado, temos a natureza orgânica e intersubjectiva do investimento, repousando principalmente sobre convenções e expectativas e, por isso, só indirectamente se relacionado os

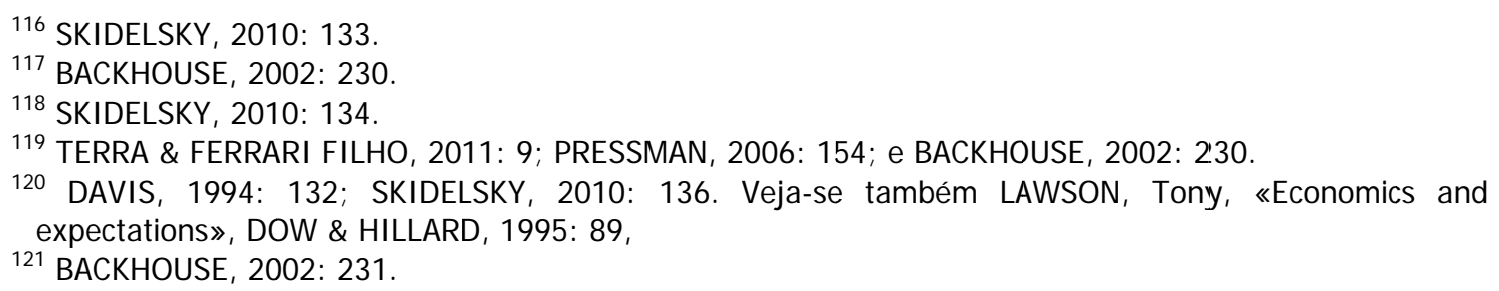


preços com as forças fundamentais da produtividade ${ }^{122}$. Eram as expectativas e as decisões de longo prazo que efectivamente produziam novos investimentos e que promoviam a «ampliação da riqueza social» ${ }^{123}$, sendo delas dependente o nível de emprego, dado que, prara Keynes, numa economia em crescimento, «o desvio entre consumo e produção deve ser suprido pelo investimento, se se pretender manter o emprego pleno» ${ }^{124}$. O investimento tinha para este, como Milton Friedman realçou, um papel fulcral a desempenhar na economia ${ }^{125}$.

A taxa de juro, relembremos, é o preço que relaciona a preferência-liquidez, o desejo de possuir numerário, e a quantidade de numerário disponível. Keynes indica que a taxa de juro tem um efeito mínimo na poupança, que dependeria sobretudo do nível do rendimento, mas tem forte influência sobre o investimento, cujo aumento depende de uma redução do custo do empréstimo $^{126}$. Na sequência destas locubrações, Keynes determina o que é dito como uma armadilha de liquidez, quando a procura de numerário é tão elevada que o aumento da quantidade de numerário disponível não se traduz numa redução da taxa de juro ${ }^{127}$.

\section{A contestação dos pressupostos irrealistas}

Keynes contestou também o irrealismo dos pressupostos da Economia “ortodoxa” ou, segundo Skidelsky, mainstream, abrangendo ainda as evoluções da teoria económica pós-Keynes. Esta parte de uma série de pressupostos que não correspondiam à realidade ${ }^{128}$. Alguns deles foram já abordados, como a limitação da procura pela oferta, a neutralidade da moeda, a igualdade entre poupança e investimento e a racionalidade, stricto senso, dos agentes, com conhecimento perfeito. Na sua origem estão as obras de Adam Smith (1723-1790), David Ricardo (1772-1823) e Jean-Baptiste Say (1767-1832), reconhecendo terem estes sido tributários de outros e as suas teses terem sido posteriormente desenvolvidas, mas sublinhando-os por terem decisivamente marcado o pensamento económico. Porém, a estes pressupostos irrealista juntam-se outros ainda, como a auto-regulação dos mercados como o sistema mais eficiente de organização dos factores produtivos (em regime de óptimo de Pareto), por uma lógica concorrencialmente perfeita e egoística, segundo a qual ao promoverem o interesse próprio, os agentes promoveriam o interesse geral. Associado a esta ideia encontram-se os conceitos de divisão do trabalho, relacionado directamente com a abrangência do mercado, promovendo ganhos de eficiência, bem como o pressuposto da flexibilidade perfeita de salários e preços e da ausência de dívidas

122 SKIDELSKY, 2010: 135-6.

123 TERRA \& FERRARI FILHO, 2011: 9.

124 SKIDELSKY, 2010: 132.

125 BLAUG, 1990: 83. Sendo a procura a geradora de oferta e a procura estando dependente do nível de rendimento, este aumenta só se através do investimento, for criado mais emprego.

126 SKIDELSKY, 2010: 138.

127 BACKHOUSE, 2002: 231.

128 SKIDELSKY, 2010: 94. 
contratuais. Haveria, por isso, benefícios na não-intervenção governamental na economia. Em suma, falamos do princípio dos mercados eficientes, da "mão invisível” smithiana, e do laissezfaire $^{129}$.

\section{Os mercados (in)eficientes e as crises económicas}

A teoria dos mercados eficientes prende-se com o conceito de equilíbrios de longo prazo, isto é, com a estabilização do mercado num ponto de equilíbrio através da flexibilidade dos factores produtivos e dos preços, neutralizando a concorrência dos erros dos agentes. Os desvios eram temporários, ocorrendo ajustamentos para o retorno ao equilíbrio. A volatilidade do investimento era tida como um mero erro de curto prazo dos agentes. Esta teoria foi tomando expressão, culminando na concepção walrasiana da economia como um sisttema de equações simultâneas ${ }^{130}$.

De acordo com o que já referimos, a economia é monetária e numa economia monetária, afirma Keynes na Teoria Geral, as alterações das expectativas face ao futuro são capazes de influenciar a quantidade de emprego e não apenas a sua direç̧ão ${ }^{131}$. As forças de mercado estavam constrangidas por arranjos institucionais que eram alheios ao mercado, sendo, pelo contrário, social e historicamente determinados: era em torno deles que gravitava o sistema económico, não em torno de pretensos pontos de equilíbrio em óptimos de Pareto ${ }^{132}$.

Entre os principais arranjos institucionais encontravam-se exactamente os contratos monetários ${ }^{133}$, sendo sobre estes que assentava toda a organização económica, sendo então a rigidez salarial e dos restantes contratos monetários apenas uma convenção para minimizar a incerteza relativamente aos preços futuros de mão-de-obra e dos bens, sendo estes contratos usualmente estáveis ${ }^{134}$. Estando consagrada assim a organização económica, quando a procura diminui, não são os preços relativos que se alteram, mas antes se restaura o "equilíbrio" pela redução da produção ${ }^{135}$, atenta Keynes em respeito do pressuposto da flexibilidade perfeita dos salários.

É pertinente sublinhar que Keynes procurava as causas do desemprego. A preocupação, e não necessariamente a teoriazação, era, sim, circunstancial. Depois de uma incisiva, mas curta, recessão no início da década de 1920, o mundo vergou-se, no final da mesma, a uma expressiva depressão económica, a Grande Depressão, de natureza complexa que aqui não trataremos. É,

${ }^{129}$ BACKHOUSE, 2002: 121-3 e SKIDELSKY, 2010: 116 e ss.

130 SKIDELSKY, 2010: 119-20, 134.

131 TERRA \& FERRARI FILHO, 2011: 10, SKIDELSKY, 2010: 125.

132 DAVIS, 1994: 124.

133 CARVALHO, 2006: 9.

134 WINSLOW, Ted, «Uncertainty and liquidity-preference», DOW \& HILLARD, 1995: 230.

135 SKIDELSKY, 2010: 139-40. 
contudo, essencial deixar claro que foi um relativamente longo período que foi em geral associado com uma forte pressão deflacionária, elevadíssimas taxas de desemprego e grandes perdas, com incontáveis falências nos países, em maior ou menor grau, industrializados ou cujas economias estavam directamente envolvidas com estes.

Tendo delineado a procura agregada como fautor de oferta, é relativamente fácil compreender que o desemprego se traduz numa abrupta quebra de rendimento, que se reflecte em redução de procura, diminuição da produção e, consequentemente, do nível de emprego. Um ciclo vicioso. Foi avançada a explicação keynesiana de o principal problema económico ser a insuficiência da procura agregada, sendo o sistema capitalista de laissez-faire incapaz de garantir o pleno emprego dos factores de produção ${ }^{136}$. A dificuldade em manter uma situação de pleno emprego resultaria do carácter monetário da economia, com tudo o que isso acarreta, e da associação de uma taxa de juro de longo prazo estável com uma eficiência marginal do capital volúvel e instável $^{137}$.

Um dos grandes problemas do capitalismo de laissez-faire para Keynes era a sua incapacidade de se auto-regular e corrigir a insuficiência da procura agregada.. A persistência da quebra da procura teria como consequência o estabelecer de um equilíbrio de subemprego ou estado de repouso, ou seja, um ponto onde, claramente não estando satisfeitas as propensões psicológicas à procura individuais, se estabelecia a oferta num volume subóptimo, existindo condições para ocorrer uma maior produção ${ }^{138}$. Os acontecimentos surgem em simultâneo, não sendo possível possuir oconhecimento necessário ao auto-equilíbrio em nível de pleno emprego, seja a longo prazo, seja a curto ${ }^{139}$. Aliás, seria essa a mensagem principal da Teoria Geral para alguns economistas, como James Tobin (1918-2002) ${ }^{140}$. Existiria então a possibilidade de múltiplos "pontos de equilíbrio" subóptimos onde haveria desemprego involuntário, isto é, pessoas com vontade de trabalhar pelo salário corrente, sem conseguirem encontrar emprego ${ }^{141}$.

Um decréscimo dos salários não resolve a situação ${ }^{142}$, excepto se aumentasse o nível de procura efectiva, «o que Keynes considerava muito improvável» ${ }^{143}$, pois não é a poupança, senão a despesa que impulsiona a produção e o emprego. A crítica à capacidade de autoregulação do laissez-faire tinha sido avançada por Veblen e depois por Wicksell $(1851-1926)^{144}$,

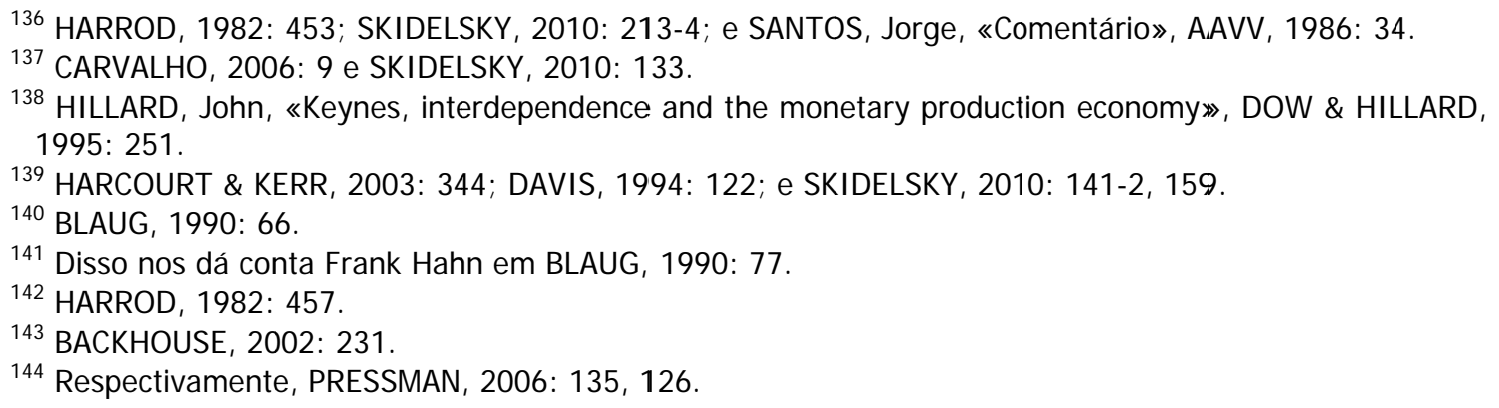


que considerava que o desemprego continuaria indefinidamente, a não ser que a política económica o corrigisse. Keynes sistematiza esta ideia: contrariamente à teoria clássica de Smith, Ricardo e Say, o mercado não se auto-regulava natural e sistematicamente em níveis óptimos e no seu máximo de potencial, nem sequer no longo prazo ${ }^{145}$.

O desvio entre o consumo e a produção teria de ser colmatado pelo investimento para se manter o pleno emprego ${ }^{146}$, o que não ocorria. A explicação repousava principalmente na preferência-liquidez e na expectativa face ao retorno do investimento, resumindo, residia, de novo, no limite, sobre a incerteza ${ }^{147}$. Falhando o investimento em ser superior à poupança, rapidamente se geraria uma situação de sobreprodução e a economia só não collapsa pela pressão que se gera para o empobrecimento da comunidade, tendente a eclipsar o excesso de poupança $^{148}$. A ênfase na importância da poupança sobre o investimento antecedeu Keynes, mas a sua preponderância tornou-se definitiva com a Teoria Geral ${ }^{149}$.

145 CARVALHO, 2006: 5-6.

146 SKIDELSKY, 2010: 132.

147 DAVIS, 1994: 133 e SKIDELSKY, 2010: 142.

148 SKIDELSKY, 2010: 141.

149 HARCOURT \& KERR, 2003: 344. 


\section{O PAPEL DO ESTADO}

Como Schumpeter (1883-1950), Keynes vê o capitalismo como inerentemente instável ${ }^{150}$. A incerteza, que podemos identificar como o elemento central da instabilidade keynesiana, campeava no modelo laissez-faire, altamente vulnerável à flutuação de convenções e expectativas $^{151}$, sendo logicamente impossível nele a eficiência ${ }^{152}$. Na sua obra The End of Laissez-faire (1926), sublinha os pressupostos irrealistas desta perspectiva, sobretudo o da atomicidade do consumo e produção ${ }^{153}$. Devido à falta da sustentação da acção humana individual, o Estado é o agente social que reúne maior quantidade e qualidade de informações dispersas, à qual se associa a sua capacidade decisiva de influência. Assim, deve preceder à coordenação da actividade económica, pois só pela coordenação da livre acção individual pode ser potenciada a liberdade individual ${ }^{154}$ e perseguido o bem comum.

\section{"Políticas Económicas Inteligentes”}

A correcção das instituições existentes não seriam suficientes para resolver o problema do desemprego ${ }^{155}$. Apenas a implementação de políticas governamentais “inteligentes” poderiam salvar o capitalismo, permitindo beneficiar dos seus atributos positivos sem ser atingidos pelo seu "lado negro" 156 . O papel do Estado deveria ser o de controlar as actividades marcadas pela incerteza e com fortes impactos sobre o bem comum $^{157}$, atenuar a incerteza em geral na realidade social e económica e promover o investimento ${ }^{158}$.

Keynes, no contexto da Grande Depressão, insurgia-se contra as políticas de austeridade. Escreveu ele que «As vozes que - numa tal conjuntura [de subconsumo e de recessão] - nos dizem que o caminho de fuga passa por uma economia de austeridade em que se deve evitar, sempre que possível, utilizar o potencial produtivo do mundo, são vozes de ignaros e de loucos» ${ }^{159}$. As flutuações, para o economista, funcionário do Tesouro Britânico desde 1915, deviam ser limitadas ao mínimo pela gestão estatal da procura através do que designava como «dinheiro barato, despesa sensata» ${ }^{160}$. Ou seja, procurou «formas de conter a instabilidade

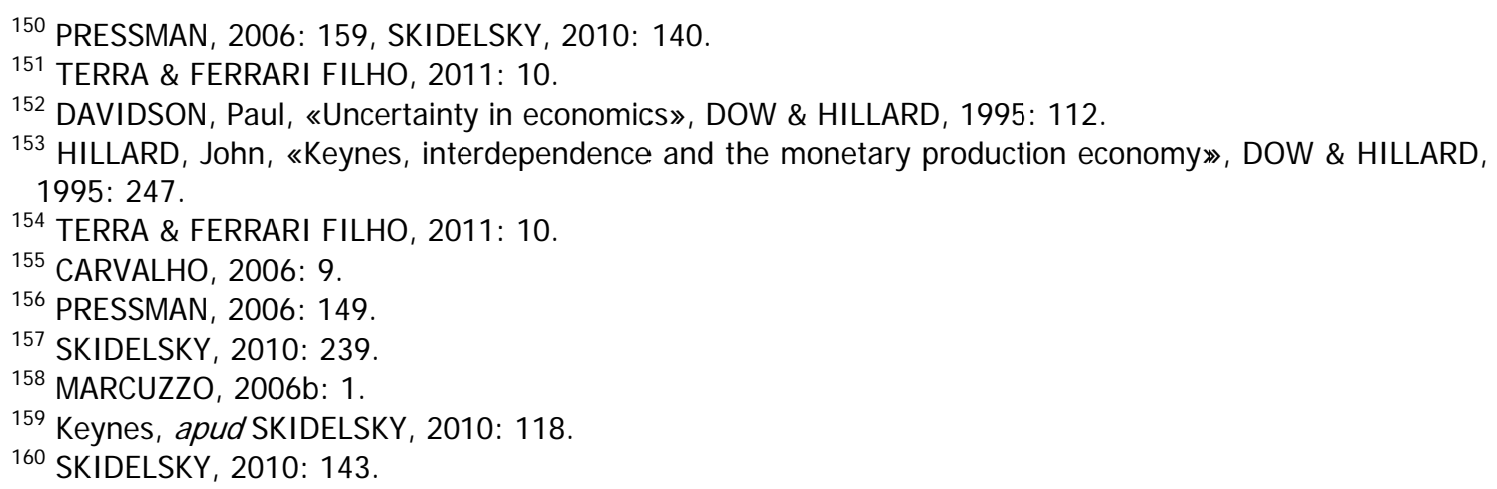


cíclica nos níveis de produto e emprego» ${ }^{161}$. Para isso actuaria ao nível da «formatação e [d]a ampliação das convenções» nas quais são baseadas as decisões dos agentes económicos, aumentando as «premissas de conhecimento directo», contribuindo para uma maior confiança nas expectativas e ainda socializando os riscos» ${ }^{162}$.

Já os mercantilistas e fisiocratas punham por condição que todo o rendilmento deveria ser reinvestido ${ }^{163}$. Não acontecendo isto, cabia então ao Estado, segundo Keynes, incentivá-lo.

\section{Taxas de juro e política monetária}

As taxas de juro deviam ser públicas e estáveis - espectáveis, poder-se-ia dizer -, de modo a constituirem um conhecimento directo, atenuando a incerteza ${ }^{164}$. Deviam ser também baixas, caso a poupança excedesse o investimento, dando então um papel importante aos bancos centrais $^{165}$. Por outro lado, deveria assegurar a estabilidade dos preços, com base na ideia de “ilusão da moeda”, sobre a qual Irving Fisher (1867-1947) tinha teorizado ${ }^{166}$. Dado que a vida económica assentava em contratos monetários rígidos, o choque monetário repercutia-se, mas lentamente, podendo as alterações da quantidade da moeda «desequilibrar as expectativas de negócio», como Keynes afirma em A Tract on Monetary Reform $(1923)^{167}$. A teoria quantitativa da moeda, segundo ele, era válida, mas apenas num momento de pleno emprego. O que importava principalmente era utilizar uma política monetária expansionista para assegurar uma taxa de juro permanentemente baixa ${ }^{168}$, uma vez que este desconfiava da efficácia da política monetária, pois operava apenas indirectamente sobre a procura efectiva, tanto no que respeita ao consumo, como ao investimento ${ }^{169}$.

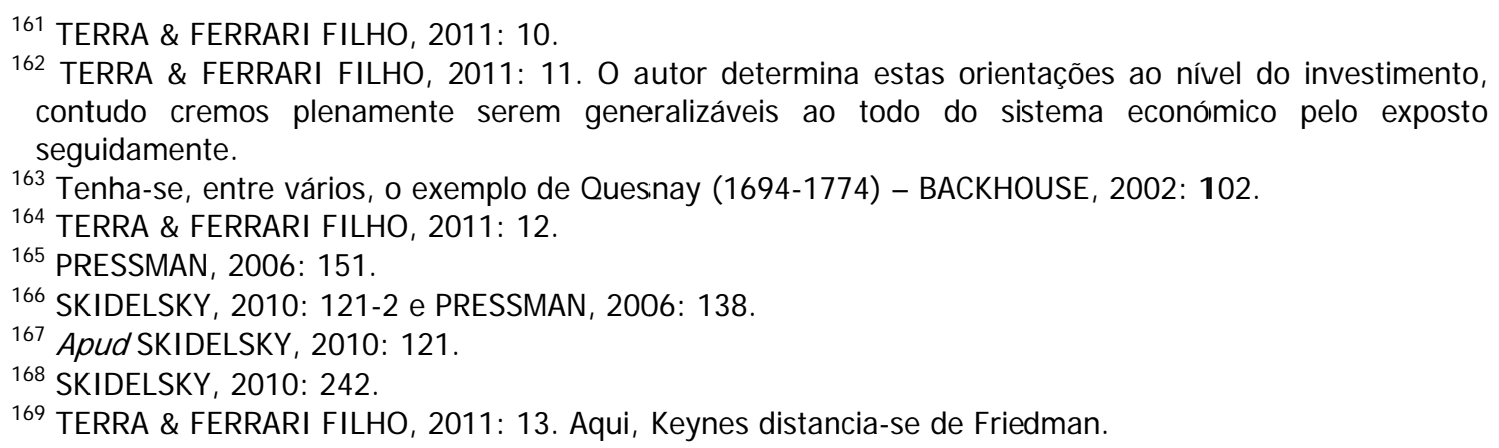




\section{O curto-prazo}

No âmbito desta conceptualização, não existe lugar para um longo-prazo equilibrado ${ }^{170}$. Este longo prazo, escreve Keynes,

é um guia enganador. A longo-prazo estaremos todos mortos. Os economistas dedicaram-se a uma tarefa demasiado fácil e demasiado inútil se, nas alturas tempestuosas apenas nos conseguem dizer que, depois de passada a tormenta, o mar voltará a acalmar. ${ }^{171}$

A curto prazo - afirma noutro lugar - ainda estamos vivos. «A vida e a história são feitas de curtos-prazos» ${ }^{172}$. Como nos indica Michal Kalecki (1899-1970), a tendêncial de longo-prazo é concretizada por uma cadeia de mudanças de curto-prazo e não uma entidade independente ${ }^{173}$. O objectivo era sustentar a procura agregada, sendo prestada uma atenção particular ao objectivo de garantir um nível de pleno emprego ${ }^{174}$. Se a confiança era reduzida devido à incerteza, o único agente capaz de eficazmente se mobilizar e injectar confiança no sistema era o Estado.

\section{Investimento público}

Devido à falha do investimento privado em suprir o diferencial entre produção e poupança, esse papel teria de ser assegurado pelo Estado, por meio de investimento público, de modo a contrariar a pressão deflacionária da poupança ${ }^{175}$, assegurando «uma socialização algo ampla dos investimentos», defende Keynes ${ }^{176}$, promovendo a propensão ao consumo e uma situação próxima do pleno emprego. De referir que o investimento público deveria ser" complementar ao privado e não concorrencial, o que se traduziria num desperdício de recursos ${ }^{177}$. É aqui que entra o famoso conceito de multiplicador desenvolvido por Richard Kahn (1905-1989) em 1931, que determina a relação entre o aumento de procura inicial e os efeitos deste sobre o consequente aumento da procura agregada, relacionando-se com a percentagem de rendimento que é convertida em procura, ou seja, com a preferência-liquidez e a propensão ao consumo ${ }^{178}$.

A circulação de riqueza a partir do capital investido e remuneração dos factores, ao que se segue acções de consumo, tem "efeitos multiplicadores" dos investimentos, pelo que a multiplicação do rendimento dos investidores teria como consequência um aumento da

\footnotetext{
170 HARCOURT \& KERR, 2003: 351.

171 Apud SKIDELSKY, 2010: 121.

172 Apud SKIDELSKY, 2010: 221.

173 HARCOURT \& KERR, 2003: 352.

${ }_{174}$ ARIENTI, 2003: 100 e SKIDELSKY, 2010: 214, 231.

175 SKIDELSKY, 2010: 242.

176 TERRA \& FERRARI FILHO, 2011: 11.

177 Segundo Kregel - $v d$. TERRA \& FERRARI FILHO, 2011: 15.

178 BACKHOUSE, 2002: 229 e BLAUG, 1990: 14.
} 
confiança $^{179}$. De referir que nos inícios da década de 1930 já era consensual que o gasto em obras públicas aumentaria o volume de emprego, como nos transparece da adopção do New Deal rooseveltiano nos EUA ${ }^{180}$. Keynes, com a ideia de "socialização do investimento", também refere a ampliação das formas de investimento, conciliando Estado e privados, ou que a disseminação do capital de um negócio fosse de tal forma elevada que de forma quasi-natural se desenvolvessem preocupações pelo bem comum $^{181}$. A questão do investimento público é importante, pois seria este um meio de persecução do bem público, dado que «There is no clear evidence from experience that the investment policy which is socially advantageous coincides with that which is most profitable», como afirma Keynes na Teoria Geral ${ }^{182}$, pelo que o Estado aplicaria medidas não no seu proveito enquanto agente económico, mas no interesse geral, algo que dificilmente seria possível com os privados.

\section{O orçamento e a política fiscal}

O investimento público deveria ser executado através da contracção de um défice do Orçamento de Estado. Contudo, Keynes não defendia orçamentos deficitários ${ }^{183}$, muito menos cronicamente deficitários, como os que se tornaram a norma no pós-II Guerra Mundial ${ }^{184}$. Deveria ter-se em conta duas parcelas distintas do Orçamento de Estado: uma corrente e outra de capital. Correspondendo «à manutenção dos serviços básicos fornecidos pelo Estado à população sob sua guarda, tais como saúde pública, educação, infra-estrutura urbana, defesa nacional, segurança pública e previdência social», o orçamento corrente deveria ser, em regra, excedentário, superando a receita corrente a despesa corrente, ou, pelo menos, ser equilibrado, igualando receita e despesa correntes ${ }^{185}$. Isto porque a existência de défices nesta componente do orçamento não gera contrapartidas lucrativas futuras, aumenta a pressão sobre a taxa de juros pela procura pública de dinheiro para saldar défices e cria o risco do Estado ter de criar nova dívida para pagar dívidas anteriores.

Por outro lado, o orçamento de capital, que se destinaria a investimentos reprodutivos estatais, com o fito de regular o ciclo económico, aumentando a procura efectiva, poderia apresentar défice, dado que, tratando-se de investimento, geraria o seu próprio superávit a prazo, equilibrando-o, embora fosse aconselhável o excedente do orçamento corrente equilibrar o défice da outra componente ${ }^{186}$. É desta maneira que se logra atenuar a desconfiança face à

\footnotetext{
179 TERRA \& FERRARI FILHO, 2011: 17.

180 BACKHOUSE, 2002: 229.

181 SKIDELSKY, 2010: 190.

182 Apud DAVIS, 1994: 164.

183 SKIDELSKY, 2010: 19, 143.

184 MARCUZZO, 2006b: 2.

185 TERRA \& FERRARI FILHO, 2011: 13.

186 TERRA \& FERRARI FILHO, 2011: 14-16.
} 
solvência estatal, não carecendo o Estado de contrair empréstimos para manter a sua actividade. É, por fim, interessante verificar que Keynes apresenta como um pressuposto a ciclicidade orçamental e, ademais, quando o confrontam com a teoria do "efeito evicção" (crowding-out) ${ }^{187}$, Keynes rejeita que em período recessivo se verifique, pois os investidores privados simplesmente não têm apetência para o investimento em face das expectativas e confiança em baixa $^{188}$.

Directamente relacionado com as políticas de investimento públiico e orçamental encontra-se a política fiscal, isto porque a despesa corrente devia ser balanceada pelas receitas fiscais ${ }^{189}$. Mas não se esgota aqui a utilidade da política fiscal. Reconhecendo que a propensão ao consumo das famílias com maiores níveis de rendimento era menor que aquelas que dispunham de menores níveis de rendimento, a política fiscal deveria ser progressiva, de modo a limitar a tendência para a acumulação de poupança pelas famílias de maiores rendimentos, que, como veremos, se associa a uma lógica redistributiva para aumentar o consumo daquelas com menores rendimentos e, logo, maior propensão ao consumo, evitando-se o engrossar do volume de poupança na sociedade ${ }^{190}$. Por este mecanismo, imediatamente se limita a progressão em direcção ao "paradoxo de prosperidade" identificado anteriormente. As desigualdades de rendimento, e de riqueza, eram socialmente injustas e economicamente ineficientes, pelo que, contrariando-as, se fomenta o incremento da procura agregada, estimulando um ambiente de igualdade de oportunidades ${ }^{191}$, reduzindo as flutuações de investimento ${ }^{192}$, diminuindo a percepção social de injustiça social, que poderia gerar conturbações sociais com consequências económicas e sociais altamente danosas ${ }^{193}$. Existindo à época teorização sobre a importância da progressividade fiscal e da despesa pública com serviços sociais, de modo a compensar desigualdades de rendimento em Wicksell, por exemplo, coube a Keynes dar-lhe protagonismo ${ }^{194}$, com uma argumentação à qual não era alheia uma sensibilidade a implicações e possibilidades práticas ${ }^{195}$.

É ainda interessante atentar em duas aproximações teóricas. A primeira é em relação a Thomas Robert Malthus (1766-1834), uma reconhecida influência de Keynes. Isto não apenas no que se refere à necessidade de realismo nos pressupostos adoptados, como veremos, mas por Malthus ter indicado anteriormente os “capitalistas” deterem um excesso de riqueza que

\footnotetext{
187 SAMUELSON \& NORDHAUS, 2005: 649.

188 SKIDELSKY, 2010: 268.

189 SKIDELSKY, 2010: 163.

190 BLAUG, 1990: 35 e CARVALHO, 2006: 12.

${ }^{191}$ KIRSHNER, 2009: 530-1.

192 TERRA \& FERRARI FILHO, 2011: 13, 16.

193 KIRSHNER, 2009: 531.

194 PRESSMAN, 2006: 129-31.

195 KIRSHNER, 2009: 531.
} 
poupavam, por não serem capazes de a reinvestir lucrativamente. A solução que aponta é similar à de Keynes: políticas económicas que desviassem deste grupo social parcimonioso o excedente que seria poupado, para ser redireccionado para o grupo dos "proprietários fundiários" que, devido à sua prodigalidade, gastaria os recursos, mantendo o fluxo no circuito, evitando-se fugas $^{196}$. A segunda é relativa aos clássicos e antecessores em geral, que criticavam fortemente as heranças, ou seja, a riqueza acumulada. Já em Locke encontramos a argumentação de que a terra deve pertencer a quem tenha capacidade (e a concretize) de a trabalhar. De Smith e Ricardo é conhecida a sua aversão às heranças, embora de natureza essencialmente diferente da de Keynes. Este, por sua vez, vê as heranças como economicamente inefiicientes, pelo que propõe altas taxas sobre as heranças, de forma a aumentar a propensão ao consumo, segundo a sua lógica de ideias ${ }^{197}$.

Por fim, para colmatar o ciclo, é preciso atentar que Keynes fecha o circuito à possibilidade de fugas do fluxo para a poupança pela política fiscal, liquidando a apetência para a poupança dos que auferem maiores rendimentos e/ou dispõem de maior riqueza, sendo recanalizada para o equilíbrio orçamental. O "paradoxo da prosperidade” seria evitado pelo incremento do investimento, para eliminar a tendência para a fuga do fluxo, aumentando a procura, mesmo quando a sociedade no seu todo fosse mais próspera.

\section{Redistribuição e o Estado-Providência}

Debrucemo-nos agora sobre como foi preconizada a manutenção da procura efectiva através da redistribuição.

Medidas de carácter redistributivo teriam para Keynes a consequência de sustentar a procura agregada. Não apenas o Estado devia intervir no circuito para estimular directamente a produção e, então, o emprego por via do gasto de investimento público, como também devia aumentar o nível de rendimento das famílias de recursos inferiores, pois têm uma propensão ao consumo superior. Como o fazer? Tal prende-se com o erigir de um modelo de EstadoPrevidência, que assegurasse a protecção contra quebras de rendimento, como as que ocorrem por via do desemprego, da doença, do acidente, da velhice e invalidez, como ainda pela orfandade e viuvez ${ }^{198}$ devendo estes esquemas redistributivos iniciar-se em períodos recessivos para fomentar um estado de procura em «quasi-boom», regularizando o ciclo ${ }^{199}$.

\footnotetext{
196 PRESSMAN, 2006: 50.

197 TERRA \& FERRARI FILHO, 2011: 13.

198 Tenha-se presente o período histórico. De facto, a assunção pelo Estado, como sua obrigação, da defesa das viúvas e dos órfãos tem fortes raízes históricas.

${ }^{199}$ CARVALHO, 2006: 18 e HARCOURT \& KERR, 2003: 346.
} 
O “relatório Beveridge”200, nome pelo qual é conhecido o relatório intitulado Social Insurance and Allied Services, apresentado por Lord William Beveridge (1879-1963) ao Parlamento britânico em 1942, foi um, senão o, mais importante marco na conceptualização do EstadoProvidência. Nele, são identificados os cinco grandes males sociais, a Escassez, a Doença, a Ignorância, a Miséria e a Inactividade ${ }^{201}$, sendo o dever do Estado combater estas "chagas" sociais $^{202}$. O relatório aborda somente a questão da Escassez, pretendendo gizar um plano para dar liberdade à sociedade face à Escassez ${ }^{203}$ através da segurança social ${ }^{204}$. Através de três elementos centrais - transferências para as famílias (subsídios de desemprego, de doença e acidente, de viuvez, reformas), um sistema de saúde compreensivo e políticas de pleno emprego -, pretende protagonizar esta reforma incisiva nas práticas políticas ${ }^{205}$.

Apesar de discordâncias passadas ${ }^{206}$, William Beveridge, no decurso do desenvolvimento do seu famoso relatório, dirige-se a Keynes para conseguir assegurar a sustentabilidade financeira do seu plano. Este mostra-se fortemente entusiasmado e desempenha um papel crucial na construção do esquema ${ }^{207}$ e no apoio político à iniciativa ${ }^{208}$. Não é de estranhar, dado que o plano pretendia aumentar os níveis de vida, reduzir a desigualdade, visava a manutenção do emprego e da procura agregada, consequentemente limitando as flutuações cíclicas e reduzindo a incerteza, tinha como pressuposto subliminar a descrença na capacidade autoregulatória e optimizante das forças de mercado desreguladas e era, além dïsso, extensivo ao todo da população e não apenas aos grupos contribuintes ${ }^{209}$. Marcuzzo, enfim, declara Keynes, a par de Beveridge, um «twin founding-father of the system [of the Welfare State]» ${ }^{210}$.

200 Vd. JUDT, 2005: 74-5.

201 Iddlessness, que é usualmente traduzida por "ócio". Cremos ser uma má tradução, uma vez que parece ter subjacente um carácter voluntário, algo que, acreditamos, não ser o sentido original, daí preferirmos o termo mais abrangente de "inactividade", que pode reportar-se a uma atitude voluntária e involuntária simultaneamente.

202 BEVERIDGE, 1995: 6.

203 BEVERIDGE, 1995: 7.

204 Beveridge define segurança social como «the securing of an income to take the place of earnings when they are interrupted by unemployment, sickness or accident, to provide for retirement through age, to provide against loss of support by the death of another person, and to meet exceptional expenditures, such as those connected with birth, death and marriage. Primarily social security means security of income up to a minimum, but the provision of an income should be associated with treatment designed to bring the interruption of earnings to an end as soon as possible» (p. 120).

205 MARCUZZO, 2006b: 3.

206 Beveridge terá sido um forte defensor do mercado-livre e do laissez-faire, chegando a director da London School of Economics (LSE), e tendo criticado fortemente a Teoria Geral após a sua publicação (1936). Surpreendentemente, as suas ideias inverteram-se e aproximou-se fortemente da lógica de ideias de Keynes. Vd. MARCUZZO, 2006b, max. 14.

207 A reacção de Keynes em carta para Beveridge: «l have read your Memoranda, which leave me in a state of wild enthusiasm for your general scheme. I think it a vast constructive reform of real importance and am relieved to find that it is so financially possible»-CARVALHO, 2006: 24.

${ }^{208}$ Não esquecer que Maynard Keynes foi Lord Keynes, com assento na House of Lords britânica.

209 MARCUZZO, 2006b: 5-10

210 MARCUZZO, 2006b: 2. 


\section{A resolução do problema político e a superação da escassez}

O’Donnell identificou diversas funções a desempenhar pelo Estado deduzido das ideias de Keynes, sendo elas: a guarda do bem comum, ser agente da racionalidade social e defensor da liberdade individual, a promoção de combinações com o sector privado, desenvolvendo também actividades tendo em conta critérios não-económicos, e devendo conduzir as suas reformas moderada e gradualmente ${ }^{211}$. Eram as políticas governamentais destinadas a resolver o problema político tal como Keynes o define: eficiência económica, justiça social e liberdade individual, do qual eram indistrinçáveis os problemas económicos do desemprego e da desigual e arbitrária distribuição de rendimento e riqueza ${ }^{212}$.

Caso as políticas certas fossem adoptadas, seria possível ultrapassar a escassez em pouco mais de uma geração, afirma Keynes. Isto implicava que, em relativamente pouco tempo, a expansão do investimento levaria a uma eficiência marginal do capital a zero ${ }^{213}$, lembrando esta expressão a ideia de estado estacionário de Ricardo e Marx (1818-1883), entre outros ${ }^{214}$. Contudo, isto não implicava a catástrofe, (havendo então similaridades com o pensamento de John Stuart-Mill). Pelo contrário, era desejável, pois aí teria a sociedade de encarardo o verdadeiro problema: viver bem, de forma agradável e sábia ${ }^{215}$.

Era o papel destas "políticas inteligentes" transformarem a sociedade ${ }^{216}$, fazendo os indivíduos valorizar os fins do sistema, viver bem, aos meios, o sistema económico em si, preferindo o bom ao útil.

Veremos de seguida que o "papel transformacional” das ideias e acções do próprio Keynes teve eco na reflexão das relações entre a economia nacional e o "resto do mundo", bem como no redesenhar do sistema internacional do pós-II Guerra Mundial.

\footnotetext{
${ }^{211}$ ANDRADE, 2000: 88.

212 TERRA \& FERRARI FILHO, 2011: 11.

213 CARVALHO, 2006: 12.

214 É curioso notar que Keynes considerava o Jaissez-faire e o marxismo partilharem a mesma base teórica económica, o legado ricardiano, que rejeitava - CARVALHO, 2006: 17.

215 SKIDELSKY, 2010: 144.

216 Skidelsky é uma das vozes isoladas que rejeita que Keynes fosse um reformador social, embora aponte as ideias acima apresentadas. Naturalmente, acreditamos, dado o exposto, ser contraditório recusar a perspectiva de Maynard Keynes como reformador social, senão até mais além.
} 


\section{O SISTEMA INTERNACIONAL E AS GRANDES GUERRAS}

Como referimos, Keynes é funcionário do Tesouro Britànico desde 1915. Aquando da negociação do Tratado de Versalhes, incorpora a delegação do Tesouro. É a sua obra que critica acutilantemente o referido tratado, The Economic Consequences of Peace (1919), que o torna famoso $^{217}$. O seu protagonismo é então indissociável do culminar da Grande Guerra.

\section{Proteccionismo e livre-cambismo}

No que respeita à sua posição face à dicotomia proteccionismo/livre-cambismo, esta foi variando de acordo com as lições da conjuntura. Se em 1923 Keynescritica o proteccionismo como incapaz de solucionar o problema do desemprego ${ }^{218}$, já com a Grande Depressão a sua postura se altera.

Veriificando a excessiva dependência do comércio externo para o crescimento económico, com consequências nefastas ao nível das relações internacionais, Keynes insurge-se «contra o fetiche do crescimento liderado pelas exportações». Apesar de reconhecer existirem as ricardianas vantagens na divisão internacional do trabalho, acreditava terem sido sobreestimadas ${ }^{219}$. Assim, apela para que o sector financeiro fosse primordialmente nacional, acreditando ainda que, sendo o problema a deflação, as tarifas aduaneiras poderiam limitar essa pressão sobre os preços. Pensava ainda que os países deviam desvincular-se do padrão-ouro para poderem determinar a sua própria política monetária, no sentido de adoptarem uma política monetária expansionista ${ }^{220}$.

O virar do avesso da teoria clássica torna-se completo com a ideia de que, dada a excessiva dependência económica das exportações, o que levava a encarar agressivamente a penetração em mercados externos, pelo que, contrariamente à ideia smithiana e afim, a globalização pode conduzir à guerra e não à harmonia, e a auto-suficiência nacional, pelo contrário, à paz ${ }^{221}$. Poder-se-ia argumentar que a História terá refutado as ideias de Keynes, uma vez que pouco depois se seguiu a II Guerra Mundial, num contexto de incremento do proteccionismo económico. Porém, tal afirmação coloca um peso injusto sobre essa doutrina económica, pois a guerra deflagrou pelo expansionismo imperialista das forças do Eixo, acontecimentos bélicos, não essencialmente económicos, sendo que, no pós-guerra, outras guerras mortíferas se sucederam num contexto de livre-cambismo e globalizaç:ão em aceleração.

\footnotetext{
${ }^{217}$ RUTHERFORD, 2005: 222-3 e KIRSHNER, 2009: 533.

218 SKIDELSKY, 2010: 250.

219 SKIDELSKY, 2010: 250.

220 Disto dá conta Keynes em «National Self-Sufficiency» (1933) - vd. JAMES, Harold, «The Fall and Rise of the European Economy in the Twentieth Century», BLANNING, 2000: 191.

${ }^{221}$ SKIDELSKY, 2010: 250.
} 


\section{Financiar a Guerra}

É exactamente na conjuntura da II Guerra Mundial que podemos colher outros contributos de Keynes. Um deles tem por designação Deferred Payments Plan, tendo consistido num plano para financiar o esforço de guerra britânico, tributando o rendimento dos indivíduos além de um determinado mínimo, numa proporção progressiva. A contrapartida oferecida era no imediato pós-guerra o Estado disponibilizar este rendimento, embora de forma mais equitativa, traduzindo-se numa alavanca para evitar uma recessão por procura insuficiente, sendo que esse dinheiro seria recuperado a prazo pelo Estado com o crescimento económico. Era, desta forma, um plano para evitar o total colapso das finanças britânicas em período de guerra, a curto-prazo, associando-lhe a preparação da retoma no pós-guerra e ainda preocupações redistributivas, aproveitando a guerra para introduzir reformas ${ }^{222}$.

A II Guerra Mundial obriga Keynes a advogar o internacionalismo, mas por razões primordialmente políticas e não económicas ${ }^{223}$. Isto porque, com o progredir da guerra e com o reduzir das reservas do Tesouro Britânico, Keynes, enquanto conselheiro do Tesouro, director do Bank of England e membro da House of Lords, realiza uma série de missõies aos EUA (seis, entre 1941 e 1946) por forma a assegurar auxílio financeiro americano, traduzindo-se no acordo Lend-Lease $^{224}$. Uma das contrapartidas exigidas pelos americanos era a abdicação pelos britânicos das tarifas imperiais preferenciais, sobre o que Keynes tinha fortes reservas ${ }^{225}$. O retorno do internacionalismo económico tinha uma explicação mais de carácter circunstancial que essencial.

\section{Por um novo sistema monetário internacional}

Foi no âmbito destas missões (sobretudo a de Junho-Agosto de 1944 e a de Março de 1946) ${ }^{226}$ que um dos mais importantes contributos de Keynes se forjou: o redesenhar do sistema monetário internacional. Foi Keynes quem esteve por detrás da filosofia de Bretton Woods ${ }^{227}$, que estabeleceu o padrão-dólar, estando as outras moedas com uma taxa de câmbio relativamente fixa face ao dólar (USD), embora ajustável, sendo o dólar convertível em ouro. Como instituições estabilizadoras do sistema encontramos o Fundo Monetário Internacional (FMI) e o Banco Internacional para a Reconstrução e Desenvolvimento (BIRD), actualmente parte integrante do Banco Mundial. Este sistema esteve vigente até 1971, com a decisão de R.

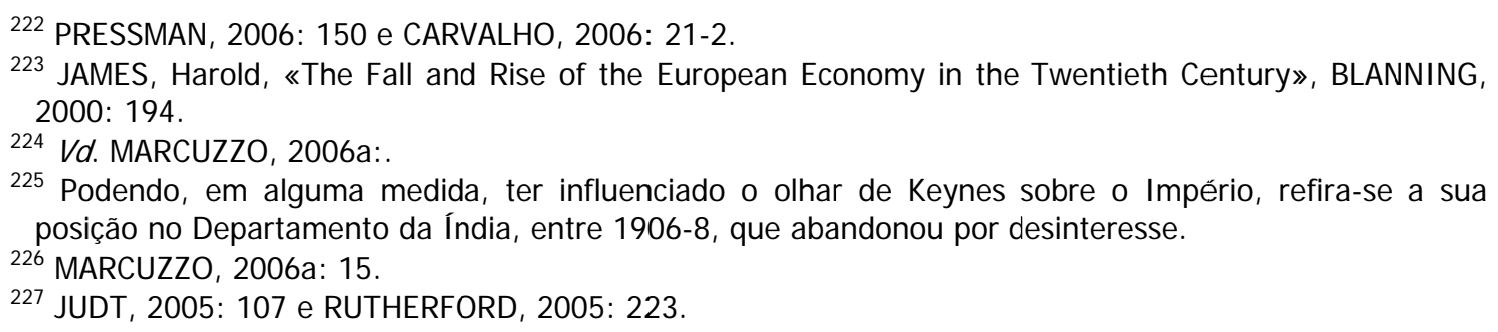


Nixon (1913-1994, presid. 1969-74) de abandonar a convertibilidade do dólar em ouro, tendo sido posteriormente substituído pelo dito "Consenso de Washington" desde cerca de 1980 (políticas neoliberais de comércio-livre, privatizações, desregulamentação, equilíbrio orçamental, taxas de câmbio flutuantes). Mostra-nos Skidelsky que, na vigência do sistema de Bretton Woods, houve «menor desemprego, um maior crescimento, uma menor volatilidade das taxas de câmbio e menor desigualdade», ao qual contrapõe o seu sucessor, que já conta com cinco recessões mundiais ${ }^{228}$.

Convém referir que este sistema de Bretton Woods só em parte corresponde à arrojada proposta de Keynes. Este pretendia, em primeiro lugar, que este novo sistema internacional permitisse aos países que apresentassem défices comerciais fosse emprestado dinheiro, penalizando os países que auferissem sistemáticos excedentes comerciais ${ }^{229}$, por meio de uma Clearing Union. Isto porque enquanto os primeiros perderiam automaticamente as reservas de ouro, sendo forçados a procurar financiar o défice comercial, estes últimos poderiam optar entre o empréstimo e a acumulação de reservas, o que imporia uma pressão deflacionária e geraria desemprego nos anteriores ${ }^{230}$, sendo injusto e ineficiente o repouso do ónus de ajustamento exclusivamente sobre os países deficitários - tal análise assenta no mecanismo de fluxo em espécie identificado por Cantillon e Hume (1711-1776) ${ }^{231}$. Assim, pretendia que existisse uma reserva monetária internacional, o bancor, administrada por um banco central com a capacidade de emitir moeda. Prevaleceu o sistema de quotas defendido pelos EUA, que rejeitam a proposta keynesiana.

Uma última reflexão sobre o sistema internacional versa sobre a regulação dos fluxos internacionais de capitais. Prudente, Keynes, como referimos, não aparentava ser muito favorável à globalização, levantando reservas em relação aos empréstimosi estrangeiros que causariam tensões e inimizades em momentos cruciais de pressão ${ }^{232}$, pelo que preferia o investimento interno. O problema era como conciliar a gestão monetária nacional com a internacional. Acreditava que os fluxos de capitais de curto-prazo deveriam ser regulados, pois, caso contrário, poderiam provocar pressões para a convergência das taxas de juro entre os países, que não lhes seriam benéficas, dada a heterogeneidade de circunstâncias que tornavam propícias políticas macroeconómicas díspares. Por outro lado, a desregulação aumentaria a incerteza, o que geraria fluxos disruptivos, desestabilizadores e disfuncionais, causando fortes flutuações nas expectativas dos investidores ${ }^{233}$. Em directa relação com o explanado

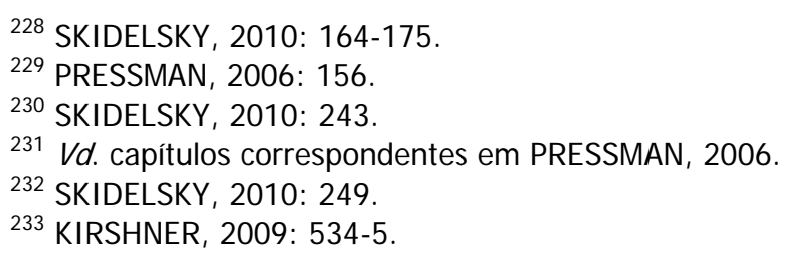


imediatamente antes, dispensamo-nos de referir que a sua lógica foi, em larga medida, ignorada, em prol da promoção de um livre-cambismo com um elevado nível de desregulação, que seria, sob uma óptima keynesiana, ineficiente, porque subóptimo.

\section{7. "REVOLUÇÃO METODOLÓGICA”}

Keynes é um dos protagonistas da reconceptualização da Economia. Para ele, a Economia estaria longe de ser uma ciência exacta, muito menos natural. Era uma ciência moral, um ramo da ética e da lógica ${ }^{234}$. Rejeita o paradigma positivista neoclássico, com o qual se pretendeu, pela matematização, cientificizar a Economia e afastá-la da Filosofia ${ }^{235}$, para, através da incerteza, introduzir ou dar relevo a uma série de elementos sistematicamente ignorados: motivos, expectativas, convenções, instituições, dinâmica. Era um "filósofo-economista”, tal como o tinham sido Smith, Mill e Marx ${ }^{236}$. É de tal forma persistente a controvérsia que, em 1982, à afirmação de Tobin que não existiria nada de mais perigoso «do que um filósofo que sabia um bocadinho de Economia», Harvard Nozick responde «A não ser um economista que não sabe nada de Filosofia» ${ }^{237}$. Na sequência destas ideias, é pertinente mencionar que Anna Carabelli vê o Tratado sobre Probabilidades como um ensaio de Filosofia prática e ética versando sobre a aplicação da probabilidade ao âmbito das ciências morais e da conduta humana ${ }^{238}$.

Nesta parte do estudo, temos já, em maior ou menor detalhe, apresentados os mais importantes contributos de Keynes para uma possível transformação abrupta do paradigma metodológico da Economia. Aproveitamos este momento para condensá-las, realçando a sua importância e validade.

\section{Incerto, mas realista}

O princípio da incerteza afastou Keynes da excessiva matematização da Economia, que toldava uma compreensão geral, pelo que era um céptico relativamente à econometria, considerando-a uma "distracção"239. Facilmente se compreende, se nos recordarmos que ele crê que há

234 TERRA \& FERRARI FILHO, 2011: 2; NUNES, 1998: 41, 102; e ANDRADE, 2000: 91.

235 Referimo-nos à vulgarmente conhecida como "revolução marginalista" - BACKHOUISE, 2002: 166-72 -, bem como a posteriores desenvolvimentos, como o robbiniano - MARCUZZO, 2006b: 7. Tal lógica vigora ainda na "ortodoxia" teórica económica.

${ }^{236}$ ANDRADE, 2000: 76.

237 Trata-se de um faits-divers, com validade ilustrativa, referido por M. Jacinto Nunes em NUNES, 1998: 11.

${ }^{238}$ ANDRADE, 2000: 83.

239 RAVETZ, Jerry, «Economics as an elite folk-science», DOW \& HILLARD, 1995: 63 e LAWSON, Tony, «Economics and expectations», DOW \& HILLARD, 1995: 77. 
«influências de tal forma importantes que não podem ser reduzidas à forma estatística» ${ }^{240}$, além de discordar do princípio de verificação a posteriori no desenvolvimento da teoria económica, que considerava inaplicável. A teoria frequentista das probabilidades não era adequada para o estudo da generalidade da realidade complexa e incerta. Sendo a sua base filosófica, critica amplamente a racionalização benthamita, isto é, o utilitarismo, que teve como expoente as ideias de Jeremy Bentham (1748-1832).

Contra o abstraccionismo ricardiano e o irrealismo dos pressupostos da teoria clássica, Keynes não abdicava do princípio de realismo. Caso contrário, não teria qualquer utilidade prática. Em vez da sedução dos modelos matemáticos “limpos” e “elegantes”, pode-se dizer que preferiu a complexa, difícil realidade, maioritariamente não tradutível por expressões numéricas, se sequer correctamente inteligível pelo $\mathrm{Homem}^{241}$. Seria interessante analisar qual o conceito de valor subjacente à teorização keynesiana, pois pensamos existir argumentos para falar duma recuperação da ideia de valor intrínseco através do intuicionismo e da influência de Moore $^{242}$, o que também seria dificilmente transposto para um modelo matemático.

\section{Razoavelmente, orgânico e dinâmico}

Com a teoria de Keynes o postulado da racionalidade individual transforma-se. Não se abandona a ideia de o indivíduo racional, mas torna-se esse um conceito abrangente. $\mathrm{O}$ capricho, a expectativa, o estado de confiança incorporam a racionalidade humana, que cessa de ser uma racionalidade omnisciente. A capacidade de conhecer do Homem é limitada, a incerteza é uma cortina espessa que nos impede de vislumbrar sequer as consequências imediatas das acções próprias, quanto mais o panorama geral presente, muito menos futuro. O comportamento racional não é normativo: é pragmático e contingente, é razoável ${ }^{243}$, uma racionalidade prática, portanto $^{244}$.

Relacionando-se-lhe encontra-se a translacção de uma concepção atomicista da sociedade para uma orgânica, o que permite a distinção entre microeconomia e macroeconomia. O indivíduo não existe fora da sociedade, pelo contrário, o processo de individuação é coetâneo com o processo social, como nos dá conta o referido ensaio de Elias. «Keynes salvou a

\footnotetext{
240 Apud, SKIDELSKY, 2010: 131.

241 Vd. SKIDELSKY, 2010: 116, 123, ANDRADE, 2000: 78, 92. De ressalvar, de novo, a influência malthusiana, que, em missiva para Ricardo, escreve: «sinto inclinado a referir-me frequentemente às coisas como elas são, sendo essa a única forma de tornar aquilo que escrevemos útil, do ponto de vista prático, à sociedade» - apud SKIDELSKY, 2010: 120.

242 NUNES, 1998: 79. Skidelsky também tem uma passagem na sua apresentação resumida de Keynes na qual refere que Keynes teria tido a percepção de que as acções da holdings americanas «estavam a deprimir muito abaixo do seu valor intrínseco» (itálico nosso) - SKIDELSKY, 2010: 110.

243 SKIDELSKY, 2010: 127-9; NUNES, 1998: 15-7; ANDRADE, 2000: 85; e WINSLOW, Ted, «Uncertainty and liquidity-preference», DOW \& HILLARD, 1995: 222.

${ }^{244}$ ANDRADE, 2000: 84.
} 
Economia das suas amarras metodológicas [da Economia “ortodoxa”] restaurando o papel do indivíduo-decisor num universo interdependente, temporal e orgânico» ${ }^{245}$. Mais, todo o sistema é dinâmico, com flutuações, transformações, múltiplos “equilíbrios” subóptimos.

\section{Observação vigilante}

A Economia, para Keynes, não era metodologicamente compatível com a verificação $a$ posteriori das proposições empíricas, rejeitando tanto a sua validação, como a sua refutação pelo método empírico, pois, segundo ele, não existe regularidade na natureza, o tempo é irreversível, logo, as condições de partida são sempre diferentes ${ }^{246}$. Uma perspectiva verdadeiramente heraclítica.

Por outro lado, vê a Economia como uma arte ou forma de pensar, caracterizada pela “observação vigilante” que permita escolher bons modelos, que captem de forma apropriada o papel preciso das convenções num dado momento, associado às atitudes e propensões psicológicas presentes ${ }^{247}$. Daqui se pode retirar que o desempenho do economista é contínuo e tem de contemplar várias perspectivas do real-social apontado por Sedas Nunes ${ }^{248}$, associando uma forte ligação entre teoria e prática ${ }^{249}$.

\section{“Babilónia”}

Keynes parte do pressuposto epistemológico que o conhecimento completo, perfeito, é inalcançável. Persistirá sempre incerteza. Assim, é-lhe associado um modo de pensar babilónico, ternário, contrário ao pensamento cartesiano, dual, onde não existe espaço para a incerteza $^{250}$. Antecipa assim as modernas correntes pós-positivistas, dando mostras disso aquando da sua superação da lógica formal, ao ampliar a noção de conhecimento, abrangendo lógica formal e humana, que não se contrapõe, mas se complementam.

Em directa relação está a redignificação da linguagem comum, substancial, aberta e adequada a raciocínios não-demonstrativos, capazes de abarcar a variável não-mensurável, nãoformalizável, da incerteza e todo o decorrente aparato conceptual ${ }^{251}$. Em suma, abre a Economia a todo o espectro de linguagens relevantes para o estudo da realidade: «truth does not only come in the guise of a mathematical model» ${ }^{252}$. A defesa da pluridisplinaridade e da pluralidade são

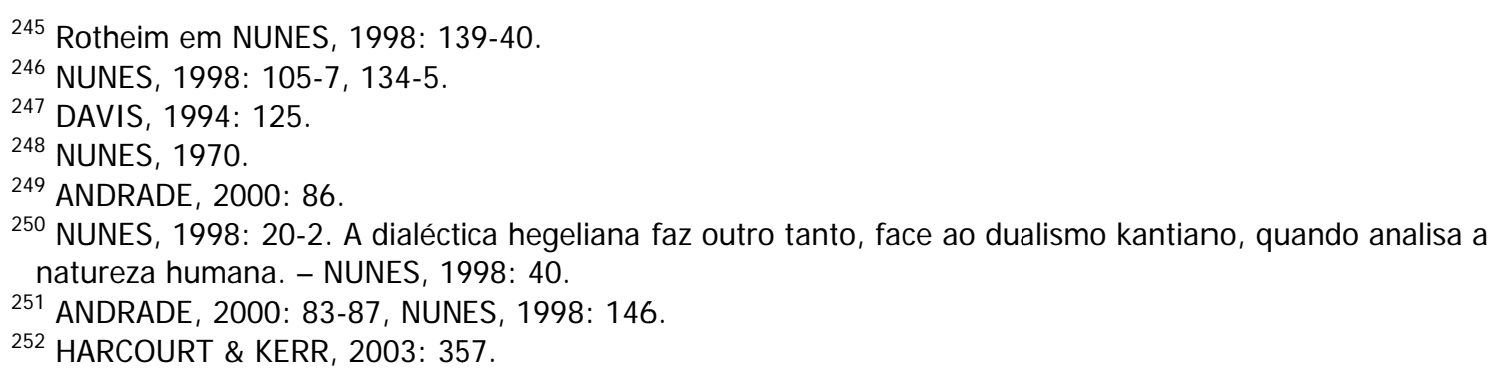


posturas que facilmente podemos entrever nas ideias de John Maynard Keynes, nomeadamente no seu famoso obituário de Alfred Marshall (1842-1924), onde, mais do que uma apologia às qualidades de Marshall, teoriza sobre as qualidades que deve ter um bom economista, enunciando todo um programa, uma postura metodológica, uma autêntica revolução na Economia $^{253}$. Para ele, não existiriam (e, para ele, não existiram) fronteiras rígidas do conhecimento ${ }^{254}$.

\section{A Economia segundo Keynes}

Consequente com as suas ideias está a tarefa que delineia para a Economia: reduzir a incerteza irredutível, que abranda ou até bloqueia o progresso económico ${ }^{255}$, mudando, moldando, o meio envolvente ${ }^{256}$. Não esquece, contudo, que o futuro não é objecto de conhecimento, «O futuro não está à espera de alguém que o aprenda: somos nós que o criamos» ${ }^{257}$. Afasta-se portanto do programa enunciado por Mill ${ }^{258}$, pelo qual a Economia se preocupa com o indivíduo, interessado (e interessada, a Economia), apenas em maximizar a sua riqueza, ou, como depois se veio a dizer, a sua "utilidade"259.

Keynes «was the right kind of an economist as an economic scientist from my point of view», declara Milton Friedman ${ }^{260}$.

\footnotetext{
${ }^{253}$ «O mestre economista deve possuir uma combinação rara de atributos (...) Deve ser matemático, historiador, estadista, filósofo - até certo ponto. Deve compreender os símbolos e exprimir-se por palavras. Deve contemplar o particular em termos do geral e tocar o abstracto e o concreto no mesmo rasgo de pensamento. Deve estudar o presente à luz do passado, em função do futuro. Nenhum aspecto da natureza do Homem ou das suas instituições deve ficar completamente fora do alcance do seu olhar. Deve ser simultaneamente determinado e desinteressado, alheio e incorruptível como um artista e, no entanto, ser por vezes tão pragmático como um político.»- Keynes, apud SKIDELSKY', 2010: 91.

254 ANDRADE, 2000: 93.

255 SKIDELSKY, 2010: 116, 131.

${ }^{256}$ MARCUZZO, 2006b: 8.

257 Como declara Skidelsky - SKIDELSKY, 2010: 130.

258 MILL, 1994.

259 KIRSHNER, 2009: 536.

260 BLAUG, 1990: 89.
} 


\section{REFORMA E SUPERAÇÃO DO CAPITALISMO}

As posições éticas de Maynard Keynes têm uma relevância significativa quando se trata de avaliar as ideias subliminares da sua teorização e sobretudo das implicações derivadas desta. Tomava uma postura crítica quanto ao contexto que o circundava, sendo legítimo, acreditamos, tomá-las como a base ética e teleológica das suas propostas, pois «A todo o sistema económico corresponde uma ética» ${ }^{261}$, inclusive àqueles que se proclamam sem ética e a-morais.

\section{Ética do investimento}

No final da sua vida, Keynes foi adoptando uma postura de responsabilização do investidor. O que queremos dizer? Que o investidor tem responsabilidades para com o bem comum, não devendo ceder ao "pânico das multidões» em face da quebra da cotação bolsista, por exemplo $^{262}$. Devia combater a obsessão pela liquidez, pois a estabilidade social também é do seu interesse e esta é vulnerável às suas acções. Keynes foi assim desenvolvendo uma ética do investimento que incorpora a admissibilidade de perdas, sendo o crucial a fidelidade à tomada de opções criteriosamente determinadas.

Diz-nos Keynes:

Não considero ser vergonha nenhuma dever uma acção quando o mercado atinge o seu nível mais baixo. Não creio ser a conduta adequada de (...) um investidor [sério] vender e fugir num mercado em queda (...) Vou ainda muito mais longe. Devo dizer que é, de tempos a tempos, dever de um investidor sério aceitar a depreciação das suas participações com tranquilidade e sem se recriminar. Qualquer outra política é anti-social, destrutiva para a confiança e incompatível com o funcionamento do sistema económico. Um investidor (...) deve ter como principal objectivo os resultados a longo prazo, devendo ser julgado apenas em função destes

(John Maynard Keynes) ${ }^{263}$

\section{Crítica ao “amor ao dinheiro” e ao egoísmo}

O “amor ao dinheiro” é ainda um traço do sistema económico. Para Keynes, este só era frívolo, não se identificando com o bem, moralmente ineficaz, pois não promovia a adopção de uma vida boa, e economicamente ineficiente, uma vez que a disposição para a acumulação era um

${ }^{261}$ NUNES, 1998: 80.

${ }^{262}$ SKIDELSKY, 2010: 109-10.

263 Keynes, apud SKIDELSKY, 2010: 112.

DINÂMIA'CET - IUL, Centro de Estudos sobre a Mudança Socioeconómica e o Território ISCTE-IUL - Av. das Forças Armadas, 1649-026 Lisboa, PORTUGAL

Tel. 217938638 Fax. 217940042 E-mail: dinamia@iscte.pt www.dinamiacet.iscte-iul.pt 
forte travão ao progresso económico ${ }^{264}$. Quando chegasse a era da abundância, o momento em a eficiência marginal do capital fosse nula, Keynes considerou que este amor ao dinheiro seria tido como «a somewhat disgusting morbidity, one of those semi-criminal, semi-pathological propensities which one hands over with a shudder to the specialists in the mental disease» ${ }^{265}$. Daí a ênfase no «ataque à poupança, à abstinência, que era um princípio fundamental dos vitorianos» $^{266}$. De certa forma, partilha com autores da Antiguidade e com os cristãos uma série de outras posições, como a noção de justiça de preços, sendo injusta a flutuação do nível de preços $^{267}$.

Bernard Mandeville e, depois deste, Adam Smith estabeleceram que os vícios privados se convertiam em virtudes públicas, confluindo o egoísmo individual em bem comum, por via de um sistema laissez-faire e de um mecanismo de "mão invisível" que caracterizaria a autoregulação da sociedade em geral. Malthus, pela ideia de parcimónia dos capitalistas, que estava a provocar uma fuga do fluxo, fala de virtudes privadas convertidas em víciosi públicos. Keynes reconhece ambos os $\operatorname{casos}^{268}$. Daqui advém a sua concertação entre coordenação estatal com liberdade política e económica individual. A coordenação económica estatal porque, existindo falhas inerentes ao sistema económico, havendo a possibilidade da opção de investimento mais lucrativa não coincidir com a socialmente mais vantajosa ${ }^{269}$, então era necessiária a intervenção deste agente, com capacidade regulatória, correctora de disfunções e desequilíbrios e promotora do progresso Humano em direç̧ão a uma vida boa. A liberdade política e económica não é boa em si, o que a faz depender de uma justificação. Keynes olha-a como instrumental para alcançar os bens intrínsecos, uma vez que, não tendo os indivíduos conhecimento directo de estados de espírito alheios, a persecução do egoísmo, enquanto princípio de maximização e não fautor de bem comum, é superior ao altruísmo ${ }^{270}$. O interesse próprio e o interesse público não eram naturalmente conciliados ${ }^{271}$.

O "amor ao dinheiro" gerava desigualdades de rendimento e riqueza que eram economicamente ineficientes, como abordámos atrás. Keynes, como Schumpeter, não era um igualitarista: a sua visão de justiça era clássica ${ }^{272}$, sendo justa a recompensa proporcional ao

${ }^{264}$ SKIDELSKY, 2010: 198.

265 KEYNES, «Economic Possibilities for Our Grandchildren» (1930), apud WINSLOW, Ted, «Uncertainty and liquidity-preference», DOW \& HILLARD, 1995: 222.

266 NUNES, 1998: 80.

267 SKIDELSKY, 2010: 205 e BACKHOUSE, 2002: 22-4, 42-6.

268 M. Jacinto NUNES, «Posfácio», em SKIDELSKY, 2010: 265.

269 DAVIS, 1994: 164.

270 SKIDELSKY, 2010: 193.

271 NUNES, 1998: 21.

272 No sentido geral do termo entenda-se, isto é, remontando à Antiguidade Clássica. Neste caso, aristotélica. 
mérito ou à contribuição ${ }^{273}$. Contudo, era problemática a concentração excessiva, devida a instituições distorcidas, que se tornava disfuncional ${ }^{274}$ e inaceitável socialmente. As heranças, por exemplo, traduziam a concentração de riqueza sem qualquer contrapartida individual e era o princípio hereditário de trasmissão de riqueza um princípio «fraco e estúpido» ${ }^{275}$, que podia e devia ser alterado sem que a operação económica sofresse uma transformação substancial. A redistribuição de rendimento e riqueza, que preconiza, era uma questão da qual dependia a legitimidade do sistema, a justiça social e a eficiência económica, segundo estes mesmos princípios. Estamos longe e cada vez mais distantes de atingir estes ideais, havendo, por paradoxal que possa parecer, uma maior desigualdade relacionada, segundo Skidelsky, com a globalização ${ }^{276}$.

Como afirma Kirshner, «To revisit Keynes is to bring the question of inequality back toward the core of macroeconomic analysis» ${ }^{277}$.

\section{Crítica ao capitalismo}

Para Keynes, o capitalismo era uma propensão psicológica a um ganho abstracto e não um sistema de relações de propriedade, como definido por Marx, aproximando-se, ao invés, de Max Weber ${ }^{278}$. O “amor ao dinheiro” ou avareza assumia a sua forma mais absoluta, sendo o sistema capitalista «uma máquina geradora de dinheiro» e não de bens. Tinha um forte poder «para explorar o valor de escassez do capital» ${ }^{279}$ e, desregulado, tendia a aumentar a desigualdade, dando maiores rendimentos e riqueza a quem deles já dispõe, algo que o dizer popular português capta especialmente bem na expressão “o dinheiro gera dinheiro”. Por outro lado, desregulado, o capitalismo exibe uma tendência crónica para um nível subóptimo de emprego dos factores produtivos, que tende a minar a organização social e auto-destruir-se, segundo o próprio Keynes $^{280}$.

Tomar o laissez-faire capitalista como princípio absoluto de conduta transformaria a vida social numa espécie de paródia de pesadelo de um contabilista, avaliando-se cada acção pelos seus potenciais financeiros. «Destruímos a beleza do campo porque os esplendores inapropriados da natureza não têm valor económico. Somos capazes de apagar o Sol e as

${ }^{273}$ CARVALHO, 2006: 7; KIRSHNER, 2009: 531 e SKIDELSKY, 2010: 204.

274 Por funcional leia-se que resultava no estimular dos comportamentos individuais de forma que resultasse um bem maior para a sociedade no seu todo - CARVALHO, 2006: 7.

275 Apud CARVALHO, 2006: 8.

276 SKIDELSKY, 2010: 189.

277 KIRSHNER, 2009: 531.

278 SKIDELSKY, 2010: 197.

279 SKIDELSKY, 2010: 205.

280 KIRSHNER, 2009: 530-2. 
estrelas porque não pagam dividendos» ${ }^{281}$. Há limites morais ao crescimento eiconómico, declara Keynes.

\section{A "Vida Boa”}

Tal como para Santo Agostinho (354-490)282, para Keynes a procura da riqueza é um meio e não um fim. O fim, o viver bem, não está associado ao incessante aumento da riqueza, como dão conta vários estudos relativos ao bem-estar ${ }^{283}$.

Keynes afasta o utilitarismo e a busca da felicidade ou prazer das suas preocupações, pois não é linear a ligação entre bondade e prazer. O que deve ser maximizado é o bem, isto é, a bondade, e tem de se levar em linha de consideração o princípio de unidade orgânica de Moore como forma de sopesar a bondade num dado momento. A simples adição de bondade nos estados mentais individuais não é possível: «Conjunturas boas são "unidades orgânicas complexas”» ${ }^{284}$. As coisas boas são intrínsecamente boas, traduzindo-se por estados mentais atemporais onde se pode encontrar o amor, a criação, a experiência estética e a prossecução do conhecimento $^{285}$. É a consequência prática desta ideia que legitima filosoficamente a passagem da ênfase para o curto-prazo, uma vez que «a vida é para ser vivida no presente, e não no passado ou no futuro» ${ }^{286}$.

É por tomar como fito fundamental da existência a "vida boa” que Keynes se determina na neutralização das flutuações económicas, pretendendo ancorar a economia no seu potencial máximo, de forma que, obviado o problema económico, a Humanidade se dedicasse à prossecução da referida "vida boa”. Superação da escassez essa que Keymes pretendia que ocorresse num futuro próximo - primeiro três, depois pouco mais de uma geração ${ }^{287}$. À escassez se seguiria o crescimento da abundância para se alcançar a estabilidade ${ }^{288}$, isto é, a eficiência marginal do capital nula, a saturação do capital, o estado estacionário keynesianno.

${ }^{281}$ Keynes, apud KIRSHNER, 2009: 531-2. Tradução do inglês da nossa autoria.

282 BACKHOUSE, 2002: 34. Aliás, era para ele «essencial manter vivas as tradicionais resistências religiosas à busca incessante de riqueza»-SKIDELSKY, 2010: 190.

283 SKIDELSKY, 2010: 188-9.

${ }^{284}$ SKIDELSKY, 2010: 190-2.

285 NUNES, 1998: 79, 82.

286 NUNES, 1998: 79.

287 SKIDELSKY, 2010: 142, 200.

${ }^{288}$ Skidelsky reconhece-Ihe influência de J. R. Commons - SKIDELSKY, 2010: 225. 


\section{O Estado como instrumento}

Como tivemos oportunidade de notar, o Estado é uma peça central para este projecto transformacional. Havia, para Keynes, uma tendência natural para o alargamento do domínio público, recomendando-se a aplicação das ditas “políticas económicas inteligentes” tendo em vista a coordenação económica e a socialização do investimento, que provocariam mudanças a longo-prazo na sociedade, não apenas económicas, mas também psicológicas ou espirituais, como indicámos: a preferência do bom ao útil.

A política era então uma «vertente prática da ética» que procurava a melhor forma de actuação governamental, tendo por fim facilitar a procura dos "bens" aos membros da comunidade $^{289}$. A sua ideia do Governo, na realidade, era no mínimo contextual: este caberia a uma elite desinteressada que não abusaria do $\operatorname{poder}^{290}$, a quem caberia definir os padrões políticos da comunidade ${ }^{291}$. Mais impressionante é o seu tacto político. Tendo por influência uma determinada perspectiva de Edmund Burke, relacionando a política e a ética com o dever e imbuído de um princípio de moderação ${ }^{292}$, recusa o fixismo e o dogma, dado que «todos gostaríamos de tentar arquitectar a nossa própria salvação» ${ }^{293}$, isto é, devia ser defendida a liberdade para a «experimentação "político-económica”». Moderado, repudia o marxismo, chegando a descrever Vladimir Lenine como «a bourgeois of the first water» ${ }^{294}$, ainda que inicialmente tenha manifestado certa simpatia pelos princípios transformacionais que veiculavam.

\section{O capitalismo como meio para a sua própria superação}

Keynes não era um revolucionário, mas um reformista ${ }^{295}$. Contudo, não acreditamos haver margem para dúvidas: pretendendia, com as suas propostas, alcançar um "estado estacionário" caracterizado pelo máximo emprego de recursos, a partir do qual as lógicas subjacentes ao capitalismo, a propensão para o ganho abstracto, seriam substituídas por um viver bem.

Para atingir esse momento, o capitalismo era, como para Marx, um período necessário para a passagem da escassez para a abundância ${ }^{296}$. Esta lógica aproxima-o também de Schumpeter, que acredita na destruição do capitalismo pelos seus sucessos ${ }^{297}$. Se esta é uma forma de pensar socialista? Não obstante a associação de Keynes ao Partido Liberal, Carvalho

${ }^{289}$ SKIDELSKY, 2010: 216.

${ }^{290}$ BLAUG, 1990: 50-1.

${ }^{291}$ SKIDELSKY, 2010: 219.

292 NUNES, 1998: 92.

${ }^{293}$ SKIDELSKY, 2010: 251.

${ }^{294}$ RUTHERFORD, 2005: 223.

295 CARVALHO, 2006: 16.

${ }^{296}$ SKIDELSKY, 2010: 189.

297 PRESSMAN, 2006: 161. 
pensa que $\operatorname{sim}^{298}$. É discutível, certamente, mas parece-nos sintomático que Tony Judt, no capítulo intitulado «The Social Democratic Moment», cite imediatamente em primeiro lugar Keynes como ponto de partida.

Etimologicamente, as suas reformas e consequências preconizadas para o capitalismo eram radicais: alteravam-no na sua raíz, levando à sua própria sublimação.

All kinds of social customs and economic practices, affecting the distribution of wealth and of economic rewards and penalties, which we now maintain at all costs, however distasteful and unjust they may be in themselves, because they are tremendously useful in promoting the accumulation of capital, we shall then be free, at last, to discard

(John Maynard Keynes) $)^{299}$

${ }^{298}$ CARVALHO, 2006: 26.

${ }^{299}$ Referindo-se ao momento após a saturação do capital - apud, CARVALHO, 2006: 13. 


\section{ECONOMIC CONSEQUENCES OF KEYNES}

\section{A querela do legado}

Diz-nos Skidelsky que as ideias de Keynes foram aceites sobretudo por resignação ${ }^{300}$ e imediatamente os aspectos epistemológicos e o cerne dos metodológicos ignorados ${ }^{301}$. No ano seguinte ao da publicação da Teoria Geral, esta foi “sintetizada” por J. R. Hicks (1904-1989) num modelo que traduziria o sistema do equilíbrio geral IS/LM ${ }^{302}$ : era, segundo Joan Robinson (1903-1983), o abastardamento do keynesianismo ${ }^{303}$, deixando de fora a discussão das dinâmicas e das expectativas, em suma, da incerteza ${ }^{304}$. Este "keynesianismo ortodoxo", baseado na "síntese neoclássica”, recalca os ensinamentos sobre a incerteza, a irreversibilidade do tempo, a centralidade da procura efectiva e sobre o papel desempenhado pelo dinheiro ${ }^{305}$. O que é usualmente considerada como uma política económica “keynesiana” tem, na verdade, muito pouco a ver com a teorização de Keynes relativa à sociedade e à ética ${ }^{306}$.

Por outro lado, o pós-keynesianismo ${ }^{307}$, que se constituiu como recuperador dos conceitos fundamentais de Keynes esquecidos pelo keynesianismo bastardo, foi incapaz de avançar com uma forma de incorporar a informação não-quantitativa na teoria, aponta Fitzgibbons ${ }^{308}$.

\section{As acusações contra o keynesianismo}

Muitos téoricos apontaram as ideias de Keynes como fundadas no seu contexto histórico. Podemos asseverar que as circunstâncias históricas, a sua vivência pessoal, influenciaram a sua percepção dos problemas e, consequentemente, dos meios e soluções do sistema económico. Embora seja evidente ser possível um economista viver um período onde o sistema económico entre em falência, com o volume de desempregados e o nível de miséria e desitruição de riqueza potencial, sem que isso abale a sua crença no equilíbrio óptimo de mercado, claramente não terá sido o caso de Keynes. Provavelmente por isso mesmo terá sido um fulcral referente o problema do desemprego, plasmado no equilíbrio subóptimo de emprego dos factores produtivos. Skidelsky rejeita esta acusação dirigida a Keynes com base na intervenção governamental ser um dado permanente, por o sistema concorrencial de mercado ser, por si só, o próprio causador dos desequilíbrios, e na moral e objectivos que assim Keynes delineia para a actividade

300 SKIDELSKY, 2010: 148.

${ }^{301}$ NUNES, 1998: 8.

302 FITZGIBBONS, Athol, «Keynes's policy model», DOW \& HILLARD, 1995: 212.

303 SKIDELSKY, 2010: 150.

304 BACKHOUSE, 2002: 236.

305 ANDRADE, 2000: 81.

306 DAVIS, 1994: 158.

307 ANDRADE, 2000: 81.

${ }^{308}$ FITZGIBBONS, Athol, «Keynes's policy model», DOW \& HILLARD, 1995: 213. 
económica ${ }^{309}$. A Grande Depressão terá sido um factor motivador para a sua visão? Necessariamente. Isso implica serem as suas ideias circunstanciais? Certamente que não. A inferência que usualmente se faz, como Milton Friedman ${ }^{310}$, de que a teoria foi refutada pelos factos, referindo-se à estagflação dos anos 1970, ignora que as medidas preconizadas por Keynes nunca foram implantadas na sua generalidade.

O "keynesianismo" que foi, em regra, vilipendiado pelos neoclássicos, monetaristas e outros «não foi o keynesianismo deixado por Keynes» ${ }^{311}$. Afasta-se também do plano teórico o facto de muitos dos factores que tornaram tão perturbada a década de 1970 terem tido uma origem exógena, como o caso dos “choques petrolíferos”312, que despoleta a crítica Friedman/Phelps ao "keynesianismo bastardo" ou "hidráulico", desenvolvido a partir da perspectiva walrasiana de Keynes ${ }^{313}$. Foram as políticas do "keynesianismo bastardo”, não as preconizadas por Keynes, associadas ao despesismo estatal, com a criação de défices orçamentais e crescimento desmesurado do aparelho burocrático apontado conno «indisciplinado macroeconomicamente e ineficiente microeconomicamente» ${ }^{314}$. Se no início da década de 1970 Richard Nixon afirmou «We're all keynesians now», Friedman, posteriormente acrescenta-lhe «and none of us are keynesians anymore» ${ }^{315}$, acreditando que a estagflação teria refutado Keynes $^{316}$. Foi certamente a declaração de óbito do "keynesianismo bastardo”, mas não de Keynes, declaram os pós-keynesianos.

Poderíamos dizer que a instauração, mesmo deficiente, de um consenso $^{317}$ sobre determinadas políticas derivadas da teorização de Keynes no pós-II Guerra Mundial, resultou num momento de prosperidade quase a nível mundial, superando «todos os recordes anteriores», no que ficou conhecido como os Trinta Gloriosos ou a Época Dourada ${ }^{318}$. Se da evidência histórica derivasse a legitimidade das ideias keynesianas, esta constatação seria incontornável.

\section{A pretensa falta de rigor}

Keynes foi também acusado de falta de rigor, sobretudo pela dificuldade de operacionalidade (matemática) da sua teoria das probabilidades. Como a maioria das probabilidades, para Keynes, se encontrava sob o véu espesso da incerteza, logo, não poderiam ser matematizáveis,

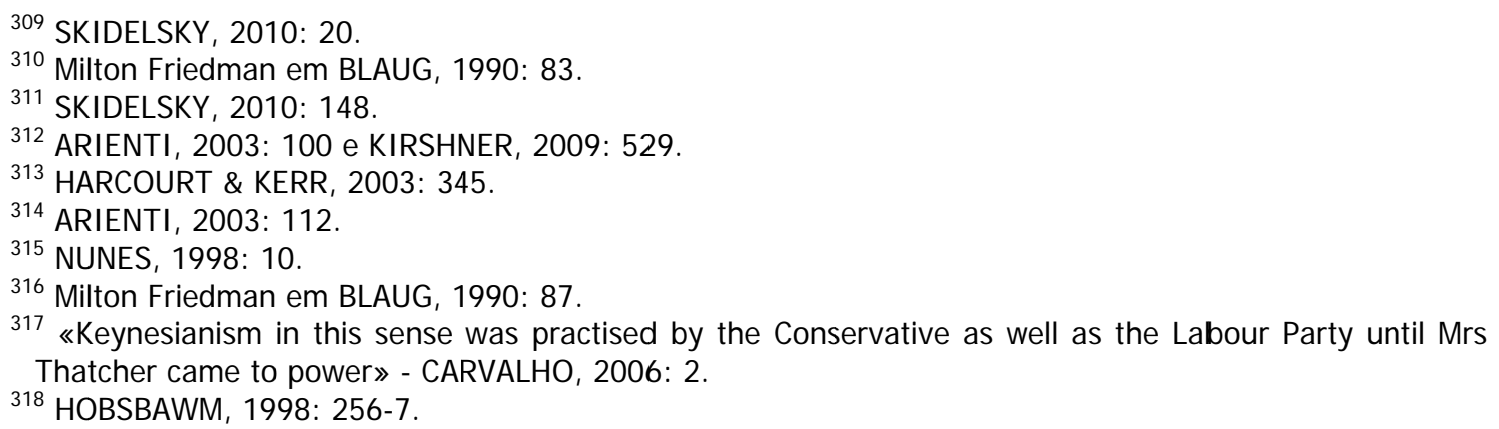


não seriam probabilidades cardinais, a conclusão imediata foi que as suas ideias não eram uma teoria exacta, pelo que o seu método era não-operacional ${ }^{319}$. Lucas considera-o «um desvio temporário do progresso científico na economia» ${ }^{320}$, ostentando uma postura contundentemente positivista, evidenciando, além disso, a crença implícita numa correlação perfeita entre matematização e cientificidade. Também a matematização da real-social, acreditamos, é, por si só, inoperacional, dada a complexidade deste que, no glossário keynesiano, tem a sua fundamentação no incontornável princípio de incerteza. O seu rigor, poder-se-ia dizer, corresponde em tentar compreender o mundo real, não rejeitando os elementos que tornam mais difícil a análise, mas integrando-os, furtando-se aos modelos que se pretendem atemporais e “elegantes”, sem qualquer correspondência com o funcionamento do sistema económico, ou seja, o seu rigor é voluntariamente limitado, em detrimento de um rigor falsamente analítico. Diz Jacinto Nunes: «A resposta racionalista à incerteza suscitada por Keynes tem sido muito simplesmente negar a sua existência. Como escreve Hahn, os argumentos dados por Keynes no capítulo XII da Teoria Geral não têm sido refutados, mas ignorados» ${ }^{321}$. A Econometria ignora a fronteira cimeira entre incerteza e risco ${ }^{322}$.

Se acaso a teoria de Keynes não traduz a realidade complexa, a visão da Economia clássica também não corresponde ao mundo em que vivemos ${ }^{323}$, sendo que não logra a Economia “pré-keynesiana” «encontrar uma saída para o desemprego generalizado» ${ }^{324}$.

\section{A reacção do laissez-faire}

Friedrich von Hayek (1899-1992) escreve, entre 1940-3, uma das suas mais famosas obras, $O$ Caminho para a Servidão. Sem dúvida também influenciada pelo contexto político coevo, Hayek insurge-se contra o centralismo estatal, pretendendo que seria o individualismo a melhor salvaguarda contra o incorrecto exercício de um forte poder acumulado, sendo o individualismo a expressão para o respeito pelo livre-arbítrio individual. A questão económica desloca-se para um plano político. O planeamento central conduziria, na sua opinião, a um caminho que, inevitavelmente, decairia no totalitarismo: «when economic power is centralized as an instrument of political power it creates a degree of dependence scarcely distinguishable from slavery» ${ }^{325}$. Era um poder excesso na sua essência, irreconciliável com a liberdade individual, pelo contrário, permanentemente subordinando a sociedade ${ }^{326}$. O sistema concorrencial, competitivo, era então o único que poderia descentralizar o poder social, reduzindo o volume

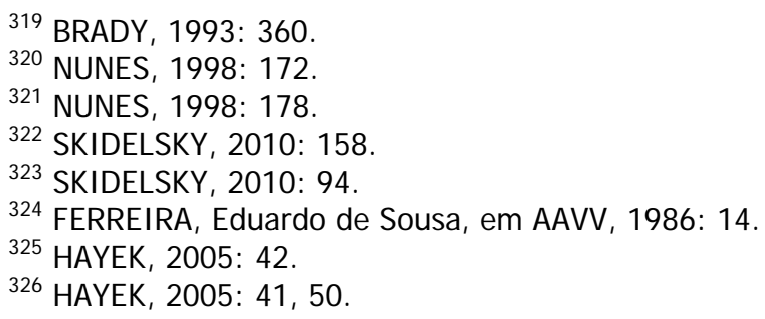


absoluto de poder do Estado sobre o indivíduo ${ }^{327}$. Apresentava também o planeamento como limitado, dada a complexidade da organização social, incapaz de supervisionar todos os factos, constantemente mutáveis. O volume de conhecimento de que um Estado dispõe era «inevitavelmente inferior ao conhecimento disperso» ${ }^{328}$ - era tosco, primitivo e limitado ${ }^{329}$. A interferência estatal no sentido de reduzir a instabilidade resultaria sempre numa redução do bem-estar social ${ }^{330}$, pelo que se posicionava com as medidas keynesianas de política económica, que acreditava aumentarem tanto a intensidade como a duração do período recessivo do ciclo de negócios ${ }^{331}$.

Tendo uma concepção política da liberdade como estreitamente vinculada ao laissezfaire, as propostas de Hayek foram qualificadas por alguns de niilistas ${ }^{332}$, dado que a incerteza radical destruiria quaisquer efeitos da acção económica estatal, inclusive o propósito da regulamentação económica, o que lhe valeu o epíteto de "anarquista liberal", dado por Fitzgibbons $^{333}$. Advoga um sistema de liberdade económica natural ${ }^{334}$, com elevados custos sociais, ameaçando a própria viabilidade da coesão social. Embora o Estado seja incapaz de deter um conhecimento perfeito, o sistema de laissez-faire, segundo as ideias de Keynes, não atingiria esse equilíbrio propalado da auto-regulação ${ }^{335}$, pelo que a sua posição imperfeita o tornava, ainda assim, no agente preferencial, dado ser aquele que maior volume absoluto de informação consegue centralizar e processar, para tomar medidas de coordenação da actividade económica. Maynard escreve então a Hayek, comentando a sua obra O Caminho para a Servidão, afirmando «what we want is not no planning, or even less planning, indeed I should say that we almost certainly want more» ${ }^{336}$. É clara a clivagem que se estabelece entre o laissezfaire e o keynesianismo no que respeita à intervenção estatal, entre, poder-se-ia associar, competição individual e coordenação social.

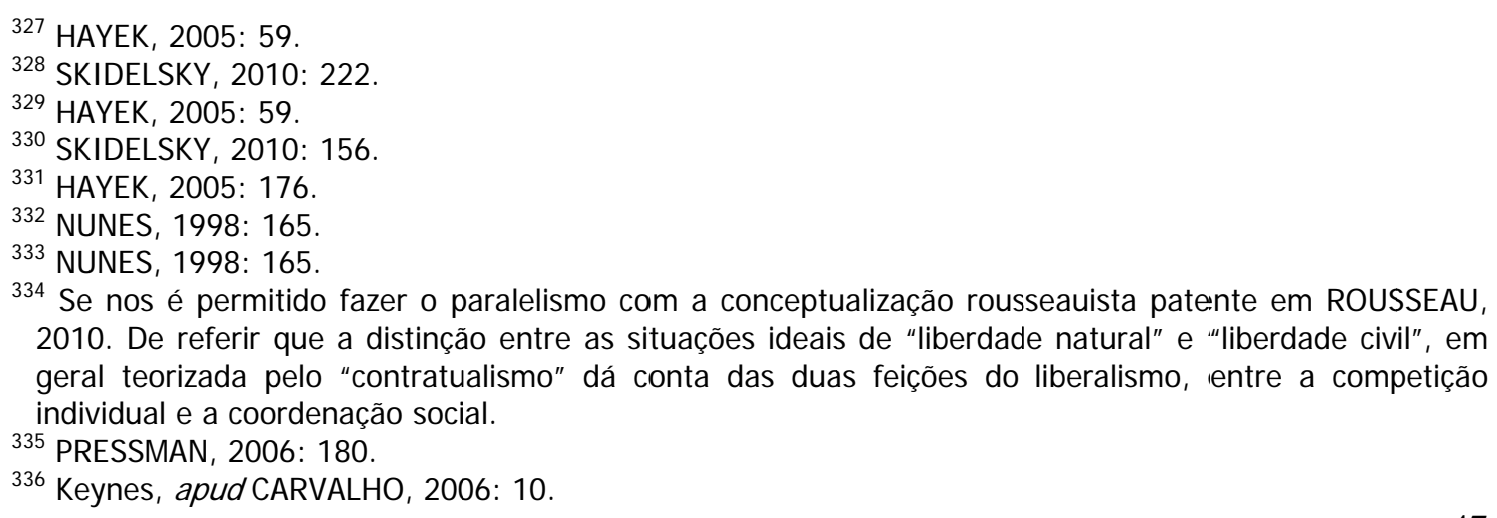




\section{CONCLUSÕES}

Tendo em mente a sua crítica à idolatrização do crescimento económico como um valor em si e não como um meio para se alcançar a "vida boa”,337, as propostas de Keynes recolocam a Economia como uma abordagem do real-social. A incerteza fundamental invalida a concepção do homos oeconomicus como objecto de estudo, substituindo o individualismo ontológico por uma abordagem organicista que afasta a intemporalidade e a constante prospecção do equilíbrio atemporal $^{338}$.

Keynes inventou a macroeconomia ${ }^{339}$. A actual visão económica do sïstema económico opera sobre um enquadramento teórico definido e elucidado por Keynes ${ }^{340}$, ainda que se tenham dispensado os conceitos keynesianos centrais, juntamente com a sua densidade interpretativa ${ }^{341}$, que agora algumas correntes da teoria económica se propõem recuperar ${ }^{342}$.

Esperamos ainda pelas repercussões da revolução metodológica de Keynes nas salas de aula.

337 SKIDELSKY, 2010: 230.

338 NUNES, 1998: 179.

${ }^{339}$ Frank Hahn em BLAUG, 1990: 76.

340 Disto dá conta o próprio Milton Friedman: «In my opinion, if you mean by Keynesian economics the theory of The General Theory, essentially none of its substance survives. What survives is its language. We all of us use the Keynesian terminology. We all of us look at the problem in a different way, because of what Keynes did» - BLAUG, 1990: 88.

${ }^{341}$ KIRSHNER, 2009: 530.

342 Skidelsky em BLAUG, 1990: 53-4. 


\section{BIBLIOGRAFIA}

AAVV, 1986, Cinquentenário da publicação da teoria geral de Keynes: comunicações e comentários apresentados na sessão inaugural do Seminário do Departamento de Economia, Dezembro 1986, Lisboa, Instituto Superior de Economia.

ANDRADE, Rogério de, 2000 (Abr.-Jun.), «A Agenda do Keynesianismo Filosófico: Origens e Perspectivas», Revista de Economia Política, vol. 20, n. 2 (78), pp. 76-94.

ARIENTI, Wagner Leal, 2003 (Out.-Dez.), «Do Estado Keynesiano ao Estado Schumpeteriano», Revista de Economia Política, vol. 23, n. 4 (92),pp. 97-113i.

BACKHOUSE, 2002, The Penguin History of Economics, Londres, Peguin Books.

BEVERIDGE, William, Social insurance and allied services. Report by Sir William Beveridge, Londres, HMSO, 1995 [1942].

BLANNING, T. C. W., 2000, The Oxford History of Modern Europe, Oxford, OUP.

BLAUG, Mark, 1990, John Maynard Keynes: life, ideais, legacy, Londres, Macmillan Institute of Economic Affairs.

BOURDIEU, Pierre, 1996, "A ilusão biográfica», M. M. FERREIRA \& J. AMADO (orgs.), Usos \& abusos da história oral, 8. ${ }^{a}$ ed., Rio de Janeiro, Fundação Getúlio Vargas, pp. 183-191.

BRADY, Michael Emmett, 1993 (Jun.), «Keynes's Theoretical Approach to Decision-Making under Conditions of Risk and Uncertainty», The British Journal for the Philosophy of Science, vol. 44, n. ${ }^{\circ}$ 2, pp.357-376.

CARVALHO, Fernando Cardim de, 2006 (Jul.), «Keynes and the reform of the capitalist social order», Rio de Janeiro, Institute of Economics - Federal University of Rio de Janeiro. Em linha [URL]: http://www.ie.ufrj.br/datacenterie/pdfs/seminarios/pesquisa/texto1303.pdf.

DAVIS, John B., 1994, Keynes's philosophical development, Cambridge, CUP.

DOW, Sheila \& HILLARD, John (ed.), 1995, Keynes, knowledge and uncertainty, [s. 1.], Aldershot Edward Elgar. 
ELIAS, Norbert, 1993, «A Sociedade dos Indivíduos», A Sociedade dos indiwíduos, Lisboa, D. Quixote, pp. 21-84.

FIRTH, Raymond, 1954 (Jan.-Dez.), «Social Organization and Social Change», The Journal of the Royal Anthropological Institute of Great Britain and Ireland, vol. 84, n. ${ }^{\circ}$ 1/2, pp. 1-20.

HARCOURT, G. C. \& KERR, Prue, 2003, «Keynes and the Cambridge School», W. SAMUELS, J. BIDDLE \& J. DAVIS, A Companion to the History of Economic Thought, Cambridge, CUP.

HARROD, Roy, 1982, The life of John Maynard Keynes, Nova Iorque, W. W. Norton Company.

HAYEK, Friedrich von, 2005, The Road To Serfdom with The Intellectuals and Socialism, [s. l.], The Institute of Economic Affairs.

HOBSBAWM, Eric J., 1996, A Era dos Extremos, Lisboa, Presença.

JUDT, Tony, 2005, Postwar - A History of Europe Since 1945, Nova Iorque, Penguin Press.

KEYNES, John Maynard, 2003 [1936], The General Theory of Employment, Interest and Money, Project Gutenberg of Australia eBooks.

KIRSHNER, Jonathan 2009, «Keynes, legacies and inquiry», Theory and Society, [s. 1.], Springer, vol. 38, pp. 527-541.

MARCUZZO, Maria Cristina, 2006a, «Keynes and persuasion» [Working Paper], DEPFID Università degli Studi di Siena. Em linha [URL]: http://www2.depfid.unisi.it/Marcuzzo.pdf.

MARCUZZO, Maria Cristina, 2006b, «Keynes and the Welfare State» [Working Paper], DEPFID - Università degli Studi di Siena. Em linha [URL]: http://www2.depfid.unisi.it/Marcuzzo.pdf.

MAURÍCIO, Carlos, 2005, A Invenção de Oliveira Martins - Política, Historiografia e Identidade Nacional no Portugal Contemporâneo (1867-1960), Lisboa, IN-CM.

MILL, John Stuart, 1994 [1836], «On the definition and method of political economy», Daniel M. HAUSMAN, The Philosophy of Economics: An Anthology, 2ª ed., Cambridge, CUP, 1994, pp. 52-68. 
NUNES, Adérito Sedas, 1970, «Questões preliminares sobre as Ciências Sociais», Análise Social, vol. VIII, n. ${ }^{\circ}$ 30-31, pp. 201-98.

NUNES, M. Jacinto, 1998, O pensamento de Keynes: aspectos epistemológicos e metodológicos, [s. 1.], Imprensa Nacional - Casa da Moeda.

O'DONNELL, Rod, 1992 (Mar.), «Keynes's Weight of Argument and Popper's Paradox of Ideal Evidence», Philosophy of Science, vol. 59, n. ${ }^{\circ}$ 1, pp. 44-52.

ORTEGA Y GASSET, José, 1999, O que é a Filosofia?, 2. a ed., [s. l.], Cotovia.

PRESSMAN, Steven, 2006, Fifty Major Economists, Londres, Routledge.

RAICO, Ralph, 2008 (Outono), «Was Keynes a Liberal?», The Independent Review, vol. 13, n. ${ }^{\circ}$ 2, pp. 165-188.

ROUSSEAU, Jean-Jacques, 2010 [1762], O Contrato Social, em colecção Livros que mudaram o mundo, Oeiras, Ed. Presença.

RUTHERFORD, Donald, 2005, Dictionary of Economics, Londres, Routledge.

SAMUELSON, Paul A. \& NORDHAUS, William D., 2005, Economia, 18. a ed., Lisboa, McGraw-Hill.

SKIDELSKY, Robert, 2010, Keynes: o regresso do mestre, Alfragide, Texto Editores.

TERRA, Fábio \& FERRARI FILHO, Fernando, 2011, «As disfunções do capitalismo na visão de Keynes e suas proposições reformistas», Revista de Economia Contemporânea, vol. 15, n. ${ }^{\circ}$ 2, pp. 271-295.

WREN, Anne, 2006, «Comparative Perspectives on the Role of the State in the Economy», em Barry WEINGAST \& Donald WITTMAN, The Oxford Handbook of Political Economy, Oxford, OUP. 